\title{
NASA Electric Aircraft Testbed (NEAT) Single-Aisle Transport Air Vehicle Hybrid Electric Tail-Cone Thruster Powertrain Configuration and Test Results
}

\author{
Rodger W. Dyson, ${ }^{1}$ \\ NASA Glenn Research Center, Cleveland, OH, 44135, USA
}

\begin{abstract}
A key technical challenge is to establish a viable concept for a MW-class hybrid gas-electric propulsion system for a commercial transport aircraft. This includes developing aircraft propulsion system conceptual designs, integrating sub-systems, high efficiency/power density electric machines, flight-weight power system and electronics, and enabling materials in high voltage insulation, high frequency soft magnetics, and conductors. The primary benefit of this research is to diversify the current turbofan propulsion options to include hybrid electric propulsion elements that reduce energy usage, emissions, and noise. A reconfigurable powertrain testbed at NASA Glenn Research Center is described including test results from the initial $500 \mathrm{~kW}$ powertrain configuration.
\end{abstract}

\section{Nomenclature}

$\begin{array}{ll}\text { COTS } & \text { Commercial off the Shelf } \\ P L C & =\text { Programmable Logic Controller for facility management } \\ \text { DAQ } & =\text { Data Acquisition System recording } \\ \text { STARC-ABL } & =\text { Single-Aisle Turbo-electric Aircraft Aft Boundary Layer Ingestion } \\ \text { ARINC } & =\text { Aeronautical Radio Incorporated } \\ \text { PowerDNA } & =\text { Compact cube interfaces to Simulink and communications } \\ \text { GUI } & =\text { Graphical User Interface } \\ \text { AC } & =\text { Alternating Current } \\ \text { DC } & =\text { Direct Current } \\ \text { CANbuS } & =\text { Controller Area Network bus } \\ \text { UDP } & =\text { User Datagram Protocol } \\ \text { NPSS } & =\text { Numerical Propulsion System Simulator } \\ \text { PLA } & =\text { Power Lever Angle } \\ \text { FADEC } & =\text { Full Authority Digital Engine Control } \\ \text { Wf } & =\text { Gas Generator Fuel Flow } \\ T-M A T S & =\text { Toolbox for the Modeling and Analysis of Thermodynamic Systems }\end{array}$

\section{Introduction}

NASA's Electric Aircraft Test bed (NEAT) is being developed to enable end-to-end development and testing of a fullscale electric aircraft powertrain. The primary purpose of the test bed is to enable the high-power ambient and cryogenic flight-weight power system testing that is required for the development of the following components to Technology Readiness Level (TRL) 6: (Dyson, 2016)

- High-voltage bus architecture-Insulation and geometry; 600 to $4500 \mathrm{~V}$

- High-power megawatt inverters and rectifiers-Commercial, in-house, and NASA Research Announcement (NRA) development

- High-power megawatt motors and generators-Commercial, in-house, and NRA development

\footnotetext{
${ }^{1}$ Hybrid Gas Electric Propulsion Technical Lead, Thermal Energy Conversion Branch, and AIAA Member.
} 
- System communication-Aircraft Controller Area Network (CAN), Ethernet, and fiber optics

- System electromagnetic interference (EMI) mitigation and standards-Shielding; DOD160(RTCA, Inc., 2010) and MIL-STD-461 (Department of Defense, 2015)

- System fault protection-Fuse, circuit breaker, and current limiter

- System thermal management-Active/passive, ambient/cryogenic, and distributed/mixed

The Advanced Air Vehicle Program, Advanced Air Transport Technology Project, Hybrid Gas-Electric Power Subproject requires this test bed to meet the subproject's technology development goals for future single-aisle commercial electric aircraft. This test facility will provide a path for full-scale powertrain component development and demonstration prior to flight.

In FY17, the NASA Electric Aircraft Testbed (NEAT) was brought online to support the first powertrain testing of subscale systems for single-aisle transport hybrid electric aircraft. The testbed passed safety reviews and operations were completed for machine pairs at the 125 kilowatt and 250 kilowatt levels, validating and maturing the strategies for using electric machine pairs to emulate a turbine engine with an integrated electrical generator, and an electric motor driving a propulsive fan. These are the key building blocks for hybrid and turboelectric aircraft powertrains, which will be built and tested at successively higher power and voltage levels, and with increasingly complex architectures toward full-scale systems over the next several years.

The first full powertrain testing is currently underway. This is a subscale, simplified powertrain for NASA's 2.6 megawatt tail-cone thruster Single-Aisle Turbo-electric Aft-Boundary Layer (STARC-ABL) concept (Welstead, 2016). STARC-ABL is a lightly distributed architecture, which pulls power off of the two under-wing turbine engines and routes power through a direct current bus to the tail of the aircraft. At the tail, an electric motor then drives a propulsive fan to provide additional thrust while reducing drag by reenergizing the aircraft's aft boundary layer found at the back of the plane. The tests, which are currently underway, are working out controls, safety and electromagnetic interference issues for this design, using non-flight-weight components at 500 kilowatts and 600 Volts. Designs for a megawatt-scale powertrain with additional systems added for energy storage, fault isolation and dynamic controls will be completed in FY18 and plans are in place to begin operations in FY19.

The reconfigurable powertrain testbed is located at NASA Glenn Plum Brook Station in the recently refurbished Hypersonic Tunnel Facility (HTF) as shown in Fig. 1. The testbed is under development to support full-scale powertrain testing under actual flight scenarios that can support cryogenic fuel, high voltage, large wingspan, electromagnetic interference, and high power research hardware. Moreover, flight altitude capability is being added to support up to 50,000 feet climbing conditions within 15 minutes in a chamber large enough to include the entire powertrain. The facility also includes $12 \mathrm{MW}$ of $4160 \mathrm{~V}$ three-phase power, $900 \mathrm{~kW}$ of water tower cooling, and a remote control room for potentially hazardous concept of operations such as liquid hydrogen. (Epstein, 2013) (Jansen, 2017) (Armstrong, 2015) (Choi, 2014) (Clarke, 2015) (Jansen, 2015) (Terorde, 2015) (Jones, 2016)

As shown in Fig. 2, the entire powertrain testbed fits within the building utilizing the exact cable lengths that would fit inside a Boeing 737-700 vehicle after being retrofitted with a tail-cone thruster. 


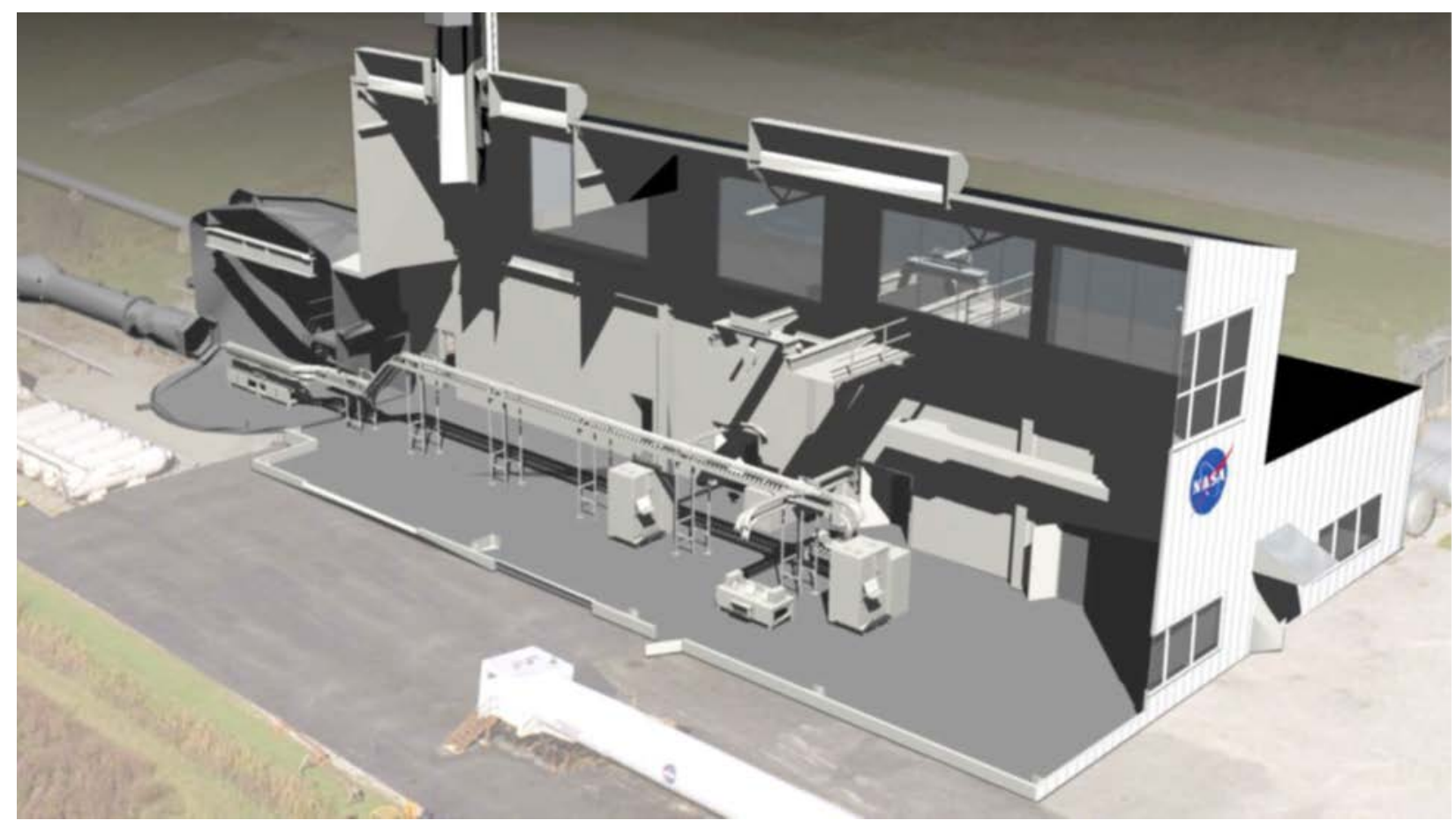

Fig. 1 NASA Electric Aircraft Testbed with STARC-ABL Configuration.

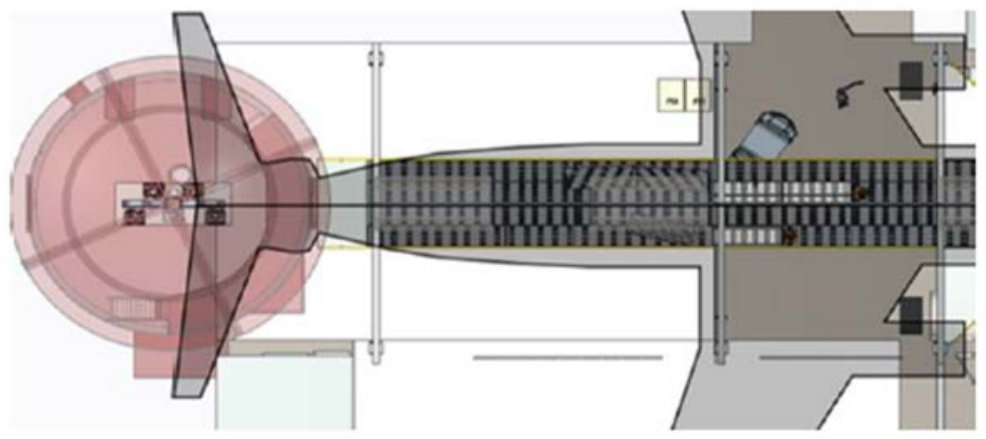

Figure 2. Top View of STARC-ABL Powertrain

\section{Basic Configuration}

Shown in Fig. 3 is the basic configuration of the NEAT STARC-ABL powertrain composed of motor pairs. Note in the figure that the Green shaded machines represent the $500 \mathrm{~kW}$ tail-cone thruster configuration that is current installed and operational, and the Yellow shaded machines are combined with the Green shaded machines to form the 1MW tail-cone thruster configuration currently under development. 


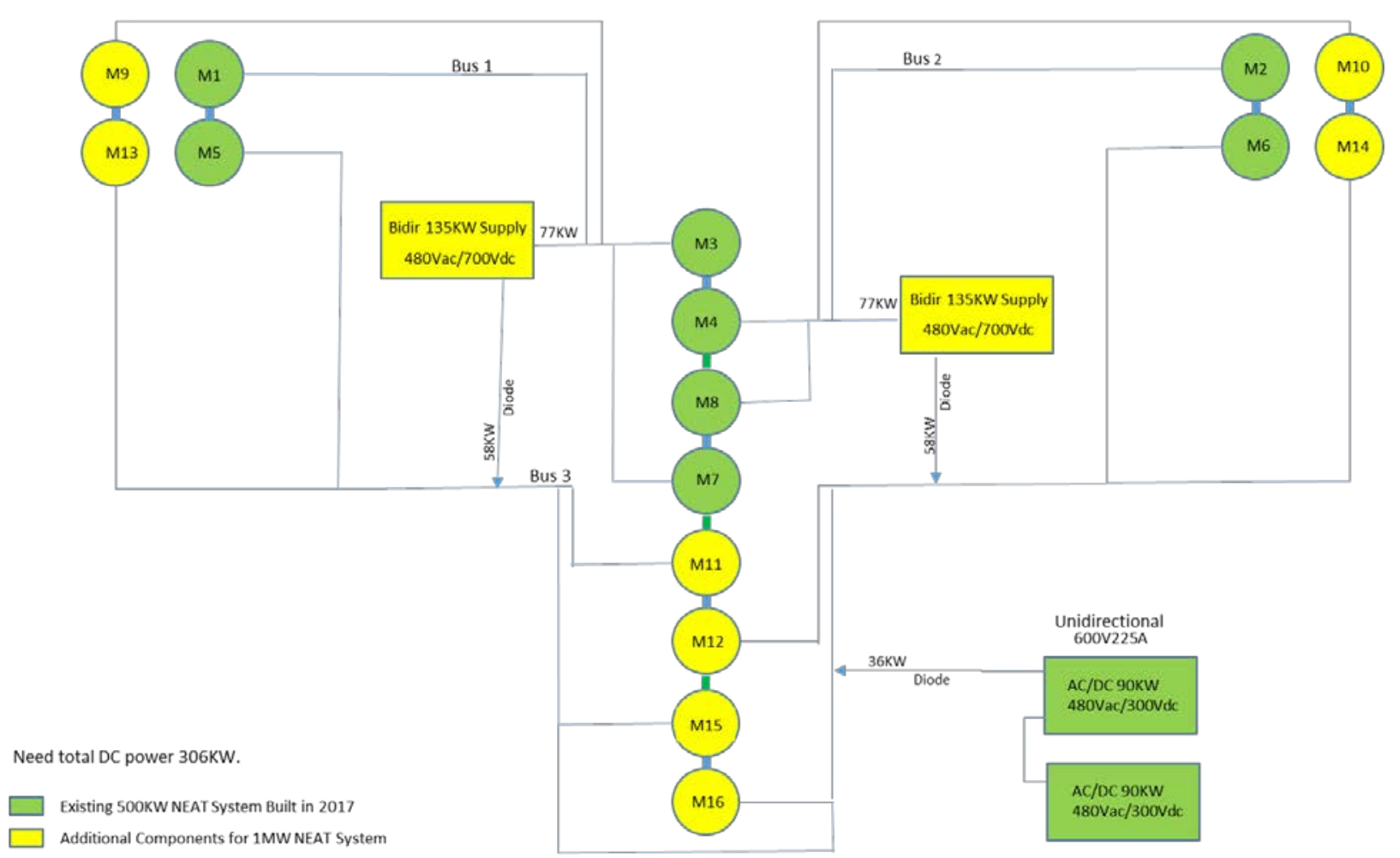

Figure 3. NEAT 1MW STARC-ABL Configuration

In Fig. 4 is the full interconnection diagram is shown including the power, communication, and fault management connections. Initially all the components are COTS sourced to provide a safe frame-work for system integration and then research components are gradually inserted into the working system. There is also a separate PLC and DAQ system to provide independent system protections and instrumentation. Also included is a water-glycol based thermal management system to provide inverter and motor cooling. The M5 and M6 motors are used to emulate turbines driving the M1 and M2 generators and represent the power extracted from the turbofans. And the M3 and M4 motors represent the tail-cone propulsor and receive their power from the turbo-generators M1 and M2. The M7 and M8 motors represent the tail-cone ducted fan and emulate the actual speed/torque curves without the need for a wind tunnel. 


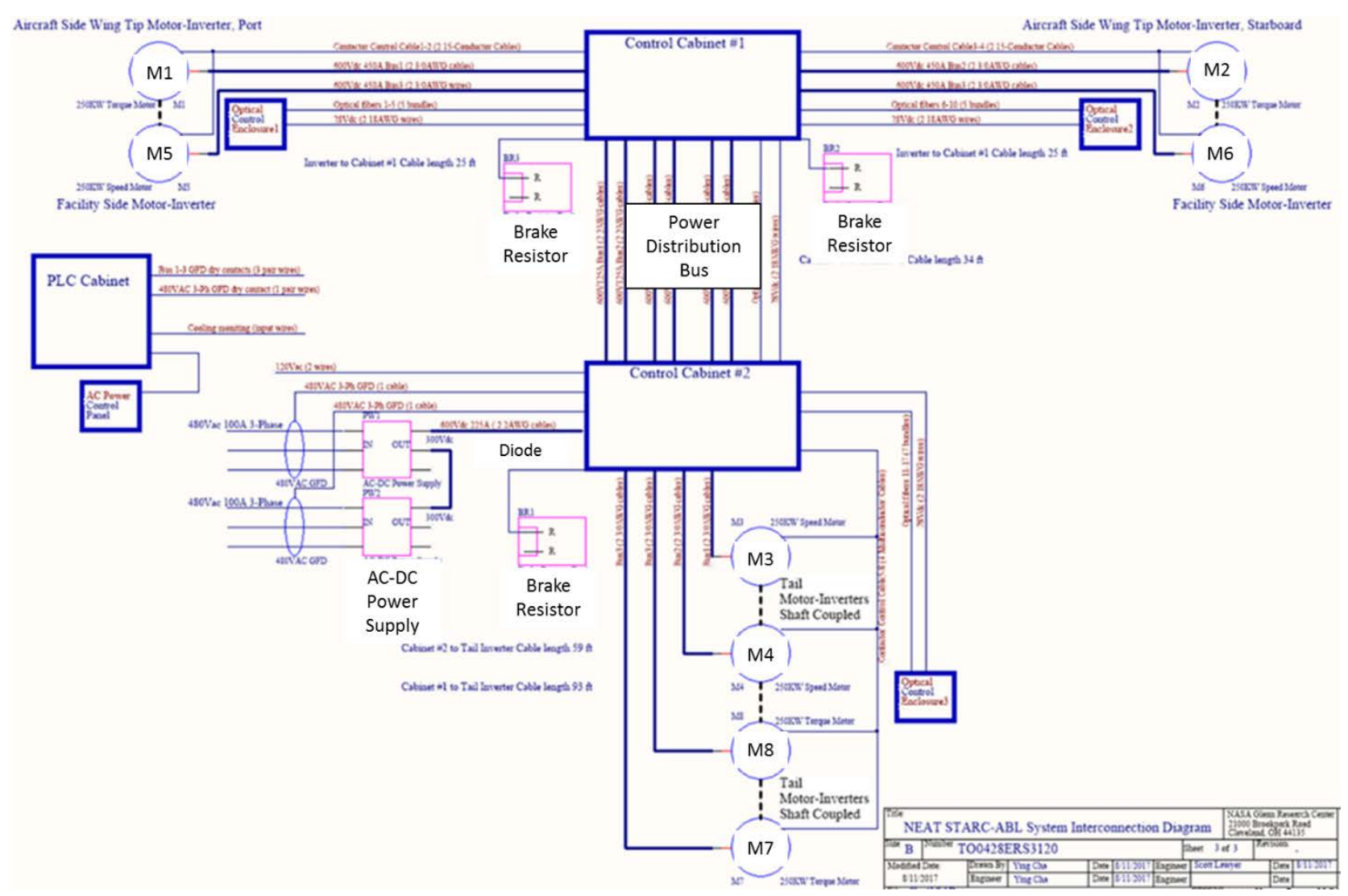

Figure 4. Full Interconnection Diagram for STARC-ABL

\section{Communication, Fault Management and Grounding}

All communication is over optical fiber with data and commands based on the ARINC 664 protocol (AFDX, 2018) which use redundant communication links. Note that the braking resistors are used to provide an upper limit voltage on the aircraft power distribution bus and the diode on the power supply provides a lower limit voltage. This insures safe operation of the testbed while operating with new control systems. In addition, ground fault detection and insulation resistance detection are employed on the AC facility side and DC aircraft side to provide early warning detection capability.

As shown in Fig. 5, the aircraft powertrain communication is handled with PowerDNA units implementing the ARINC 664 protocols and all of the machine drives utilize optical CANbus. The master PowerDNA communicates via UDP to two PCs, one is used for providing flight profile controls and the other is used for inverter diagnostics. In addition, a separate instrumentation suite system is employed to independently record all communication, power, and diagnostic information during each test.

Fig. 6 shows the basic error handling information flow diagram. Note the primary safety feature is the use of COTS inverters that provide a wide range of permissives and intelligent fault response such as any communication interruption will disable the inverters. The facility is also global monitoring for any short to ground condition to disable the whole system. Each motor pair has a dedicated powerDNA providing speed and torque commands but also communicate any errors to the inverters detected from somewhere else in the powertrain. In addition, the inverters communicate any machine levels error up to the local powerDNA and then to the master powerDNA and finally to the master PC. So full supervisory control and fault detection is maintained at the master PC GUI but flight-critical safety is managed locally at the inverter hardware level. In addition, all power distribution is fused to prevent overcurrent faults. 


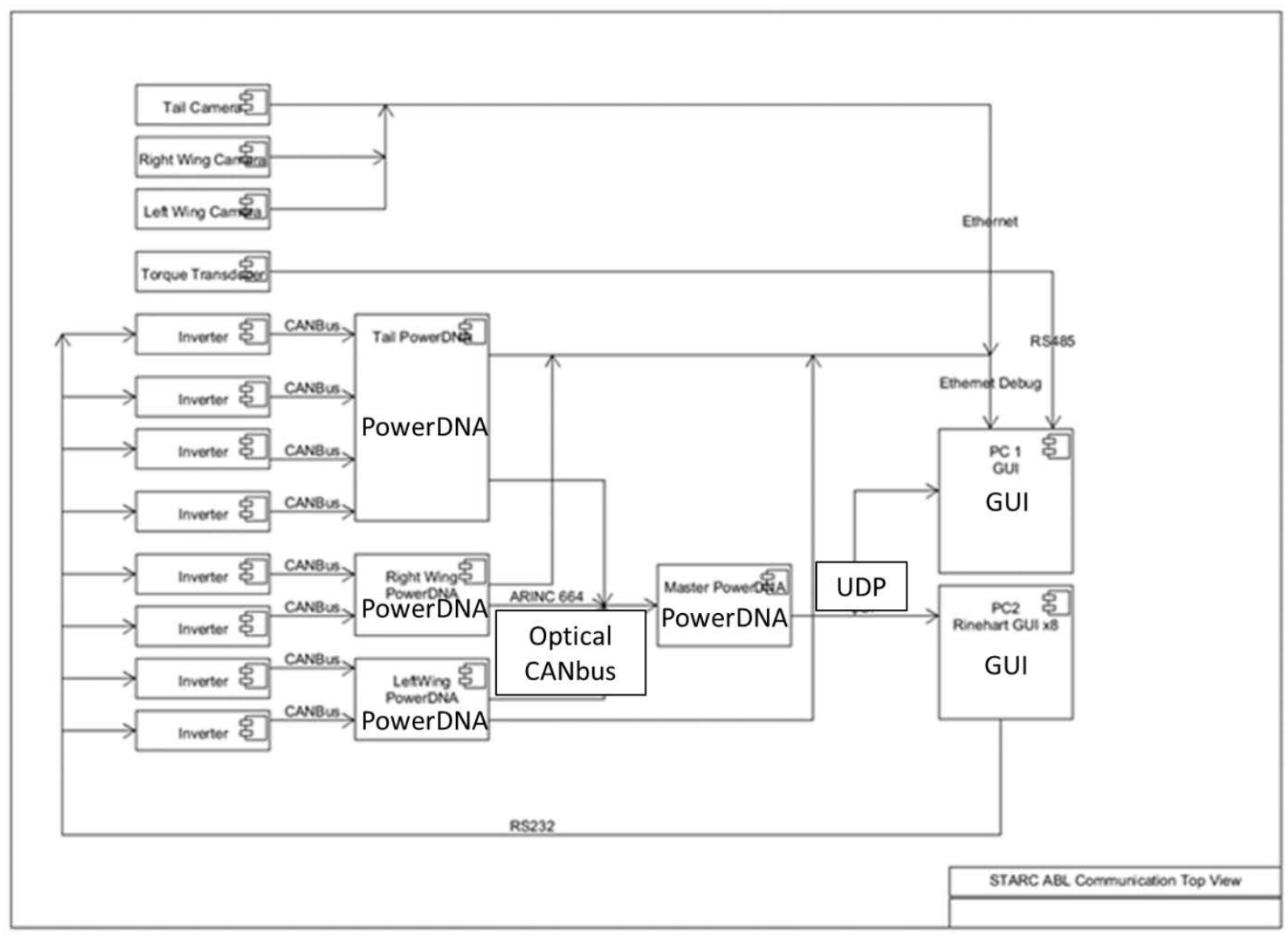

Figure 5. STARC-ABL Communication and Control

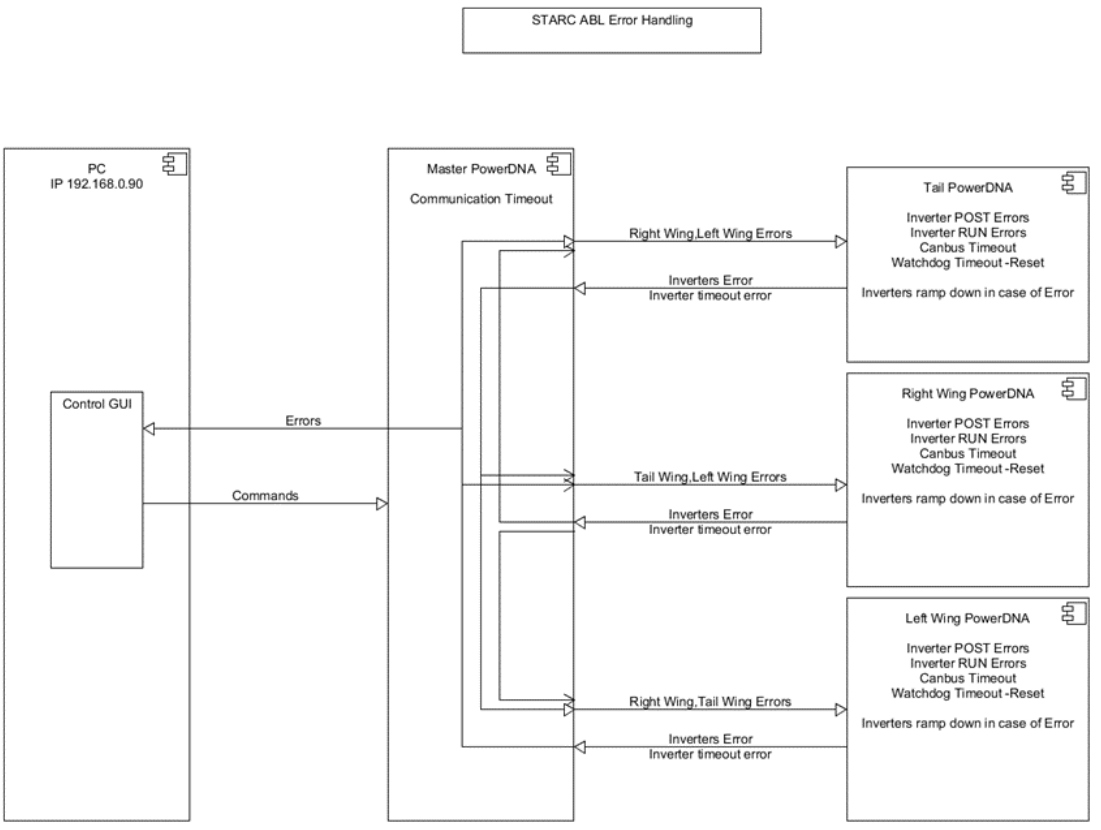

Figure 6. STARC-ABL Error Handling 
Another critical safety feature is employing a fully bonded and grounded system as shown in Fig. 7. Note all structure is grounding with less than 2 milliohm bonding resistance. For this initial setup this grounding scheme is adequate to maintain safety, but is not fully reflective of an aircraft environment. In Figs. 8-9 is shown the ground fault detection scheme employed and the isolated aircraft DC bus. All current carrying power lines are shielded on both ends.

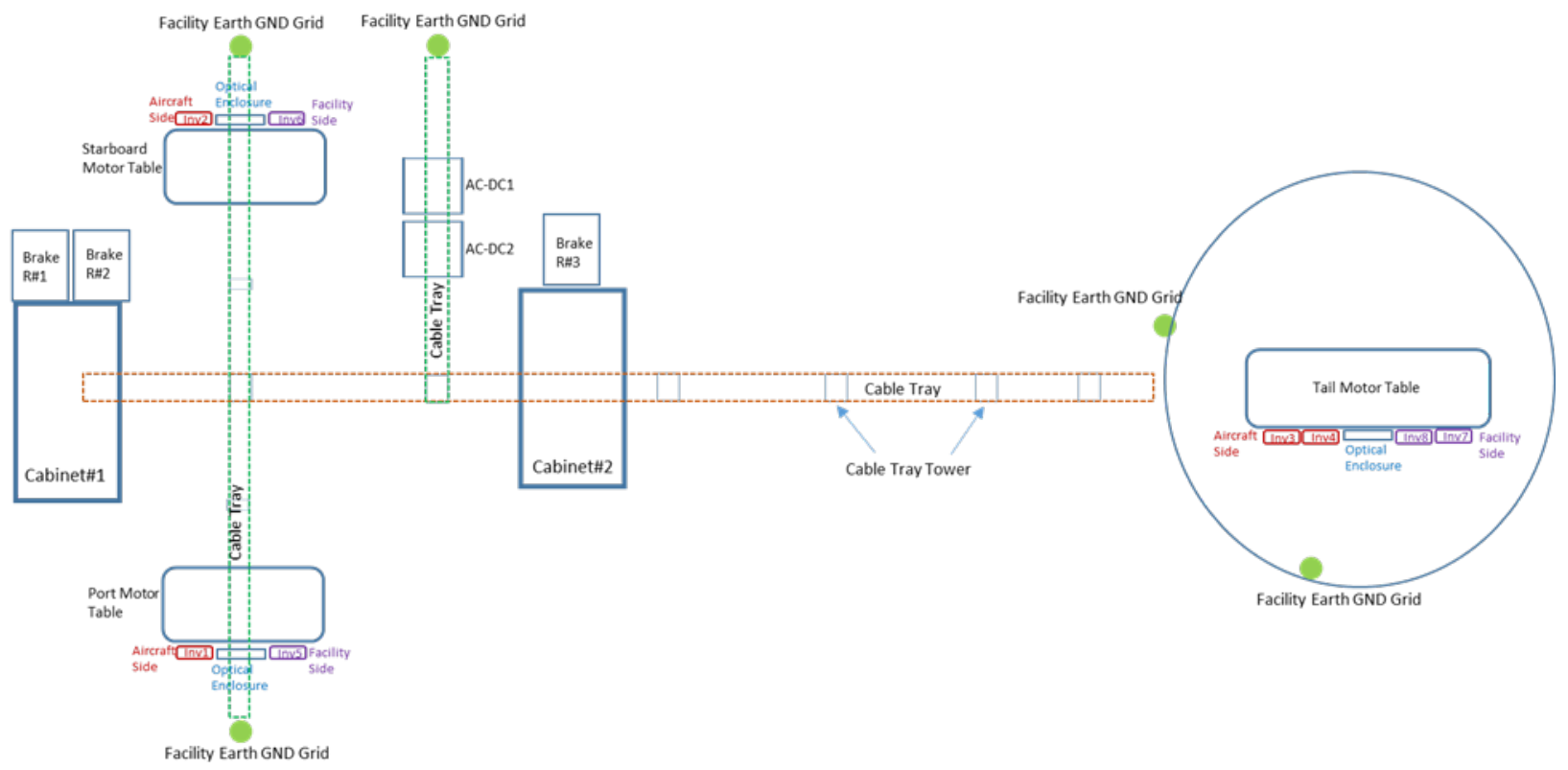

Figure 7. Current Grounding Schematic

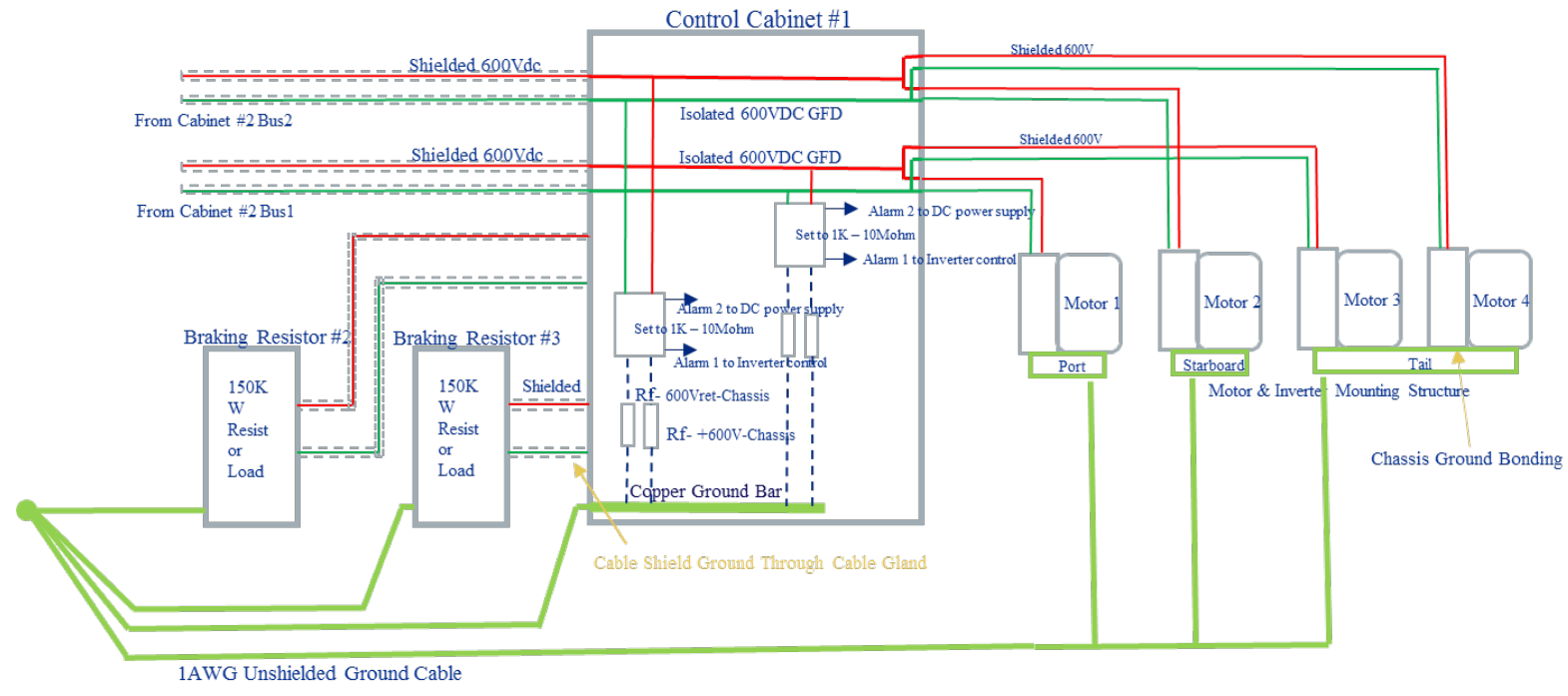

Figure 8. Cabinet \#1 Fault Management and Grounding 


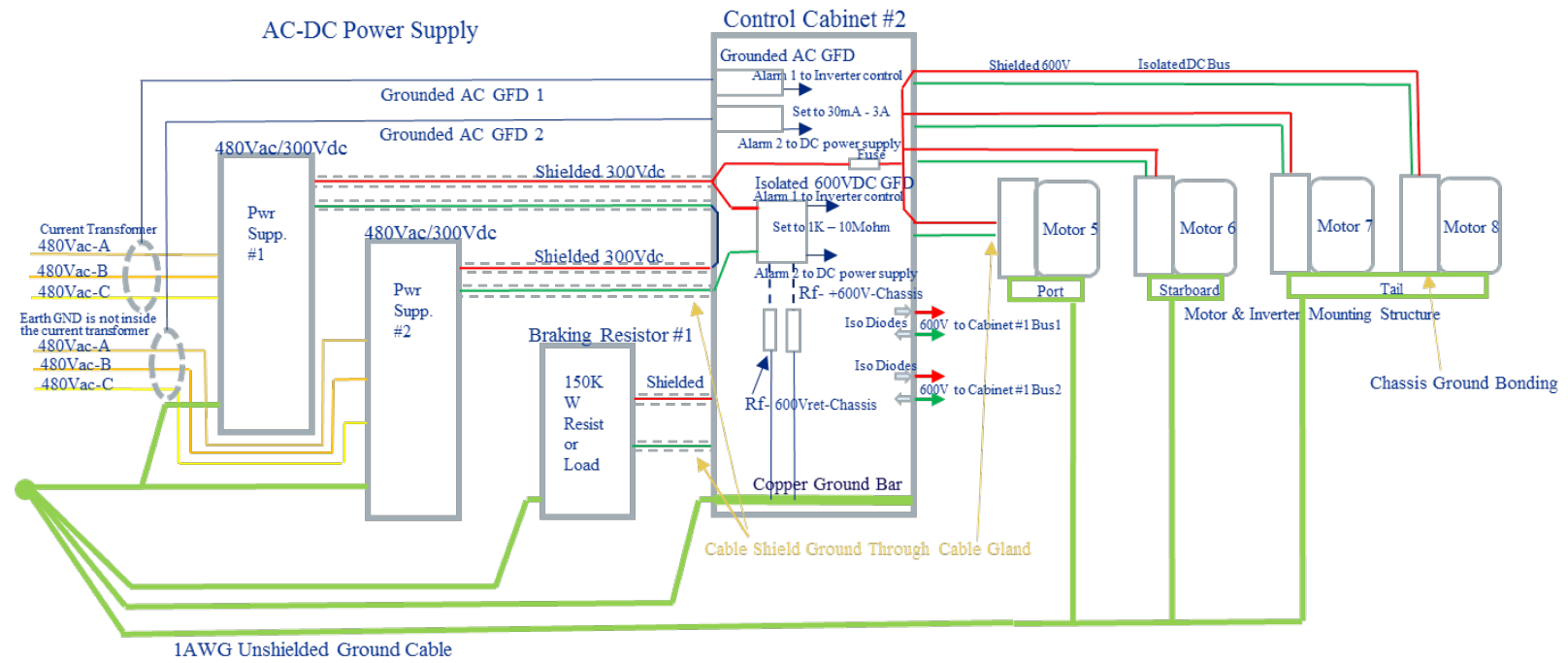

Figure 9. Cabinet \#2 Fault Management and Grounding

\section{NPSS Scaling to turbines and ducted fan}

The Numerical Propulsion System Simulator Software was incorporated into the NEAT to enable a more realistic dynamic response that accounts for the actual turbofan and ducted fan responses. NPSS is an industry standard engine cycle model that is able to model full-scale propulsor components. The NPSS was integrated into the Matlab/Simulink environment via the S-function for a common platform with other NEAT simulation tools. A Simulink UDP library block in the NPSS Simulink Simulation is used to send and receive data from the NEAT GUI that includes:

- Inputs: Altitude, Mach/Speed, PLA/Wf, Torque Electric Generator

- Outputs: Low Pressure Shaft Speed

Initial testing was completed using a pseudo-real-time block in Matlab/Simulink and full STARC-ABL system testing was recently completed as well. This simple engine model in NPSS was interfaced to the NEAT GUI without a fuel flow controller but running in pseudo-real-time to provide approximate shaft dynamic time constants. The engine model in NPSS is being improved to more accurately include operability margins. The next step would be to enable real-time simulation of the engine in either NPSS or T-MATS to enable closed loop control of the turbofan engine with power electronics hardware. This will enable the use of FADEC flight hardware to support high fidelity engine control system interactions with the power system controller to simulate overall control architecture.

Initial validation of the modeling tools was completed utilizing a single-pair of motors as shown in Fig. 10. and highlighted in Fig. 11.

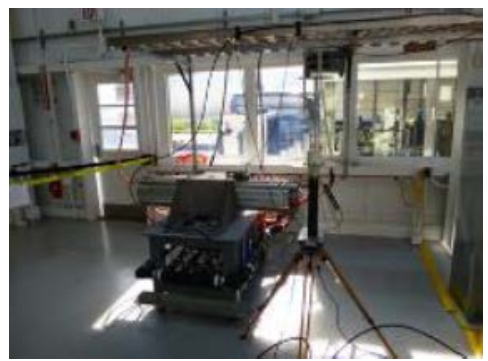

Figure 10. Initial 125kW Machine Pair Demonstration 


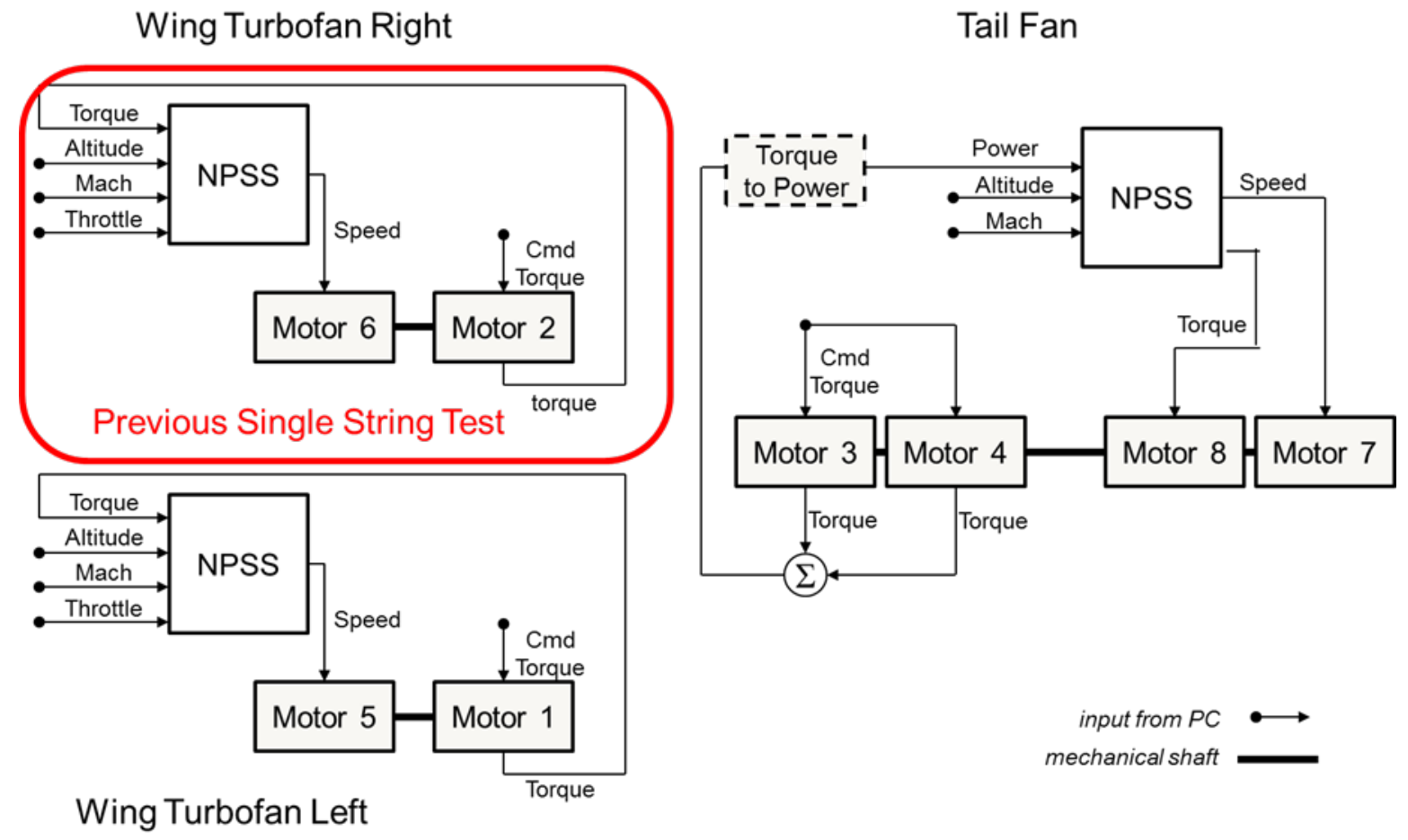

Figure 11. NPSS Control Schematic

Note in Fig. 11 that NPSS is used to provide speed commands to the turbo-generators and supplies both speed and torque commands for the simulated tail cone ducted fan motors 7 and 8.

(AFDX, 2018)

Also developed a Simulink/SimPowerSystems model of the STARC-ABL configuration of NEAT as shown in Fig. 12 that builds on the validated single-string model. It is used to analyze control schemes, operation in nominal and fault conditions, and power quality. 


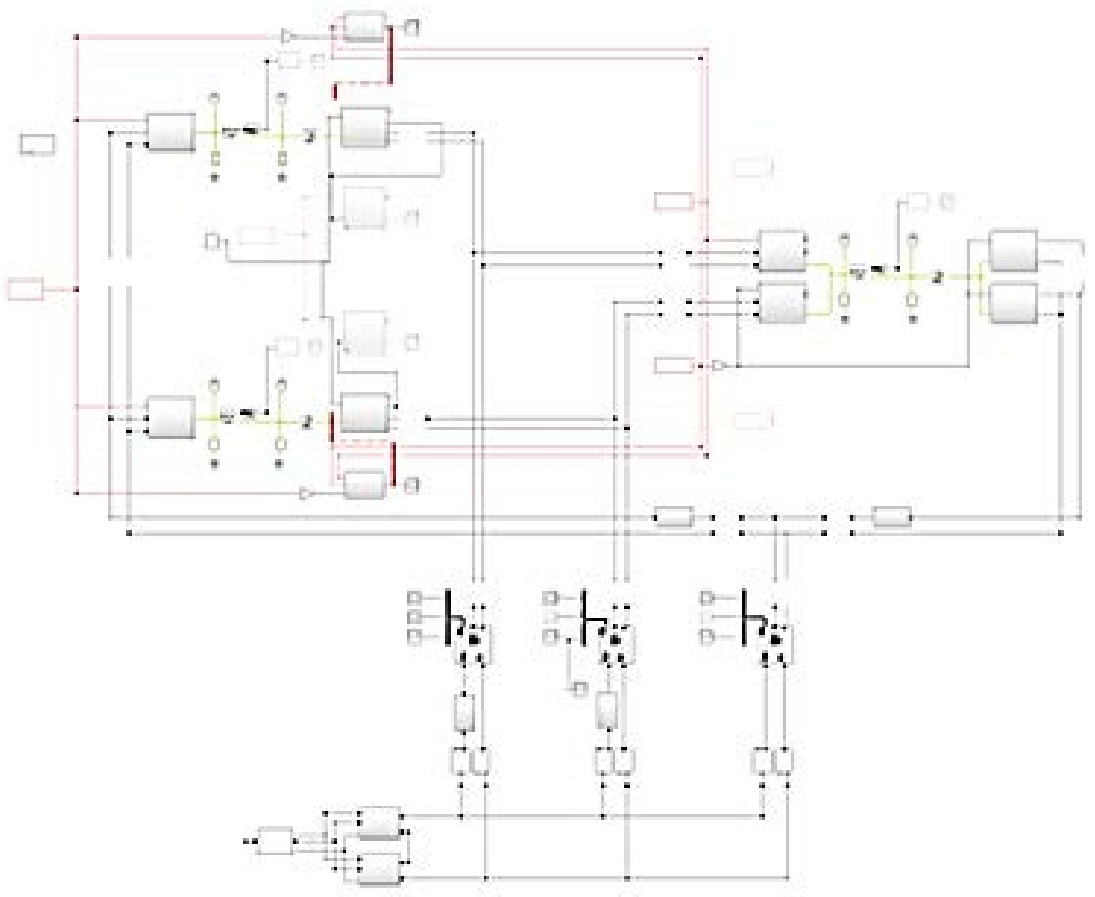

Figure 12. Dynamic Power System Model

\section{Test Results - 500kW STARC-ABL}

Results from NEAT dynamic Simulink model, in STARC-ABL configuration, were compared with test data recorded at NEAT. The Simulink model used to generate results only contained NEAT electrical system and motors and did not include NPSS. The motor commands used in the simulation were the same commands sent to respective motors.
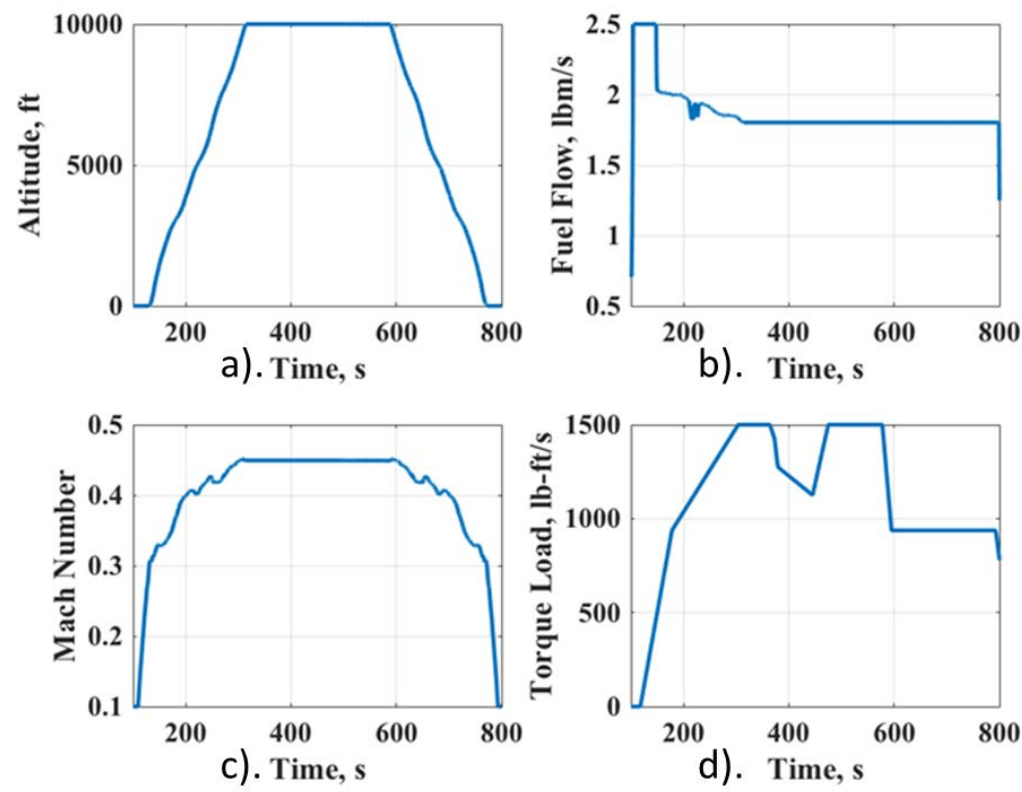

Figure 13. Flight Profile for NPSS Testing 


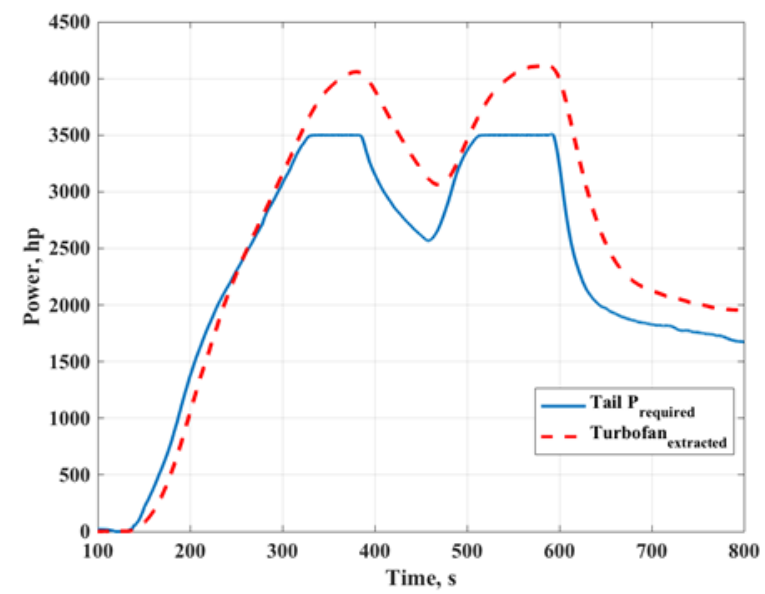

Figure 14. Power Required At Tail Fan and Turbo-Generator

The flight profile shown in Fig. 13 was used for initial NPSS testing. The NPSS inputs include the altitude, Wf, Mach number, and shaft torque. The power required by the tail fan, and the power extracted to compensate for losses in the system are provide in Fig. 14. Note the delay in the transient extraction off of the turbofans due to torque filtering. (Connolly, 2018). In the future the turbo-generator will utilize voltage control instead of speed or torque control to naturally balance the tail-cone thruster power with the generated power.
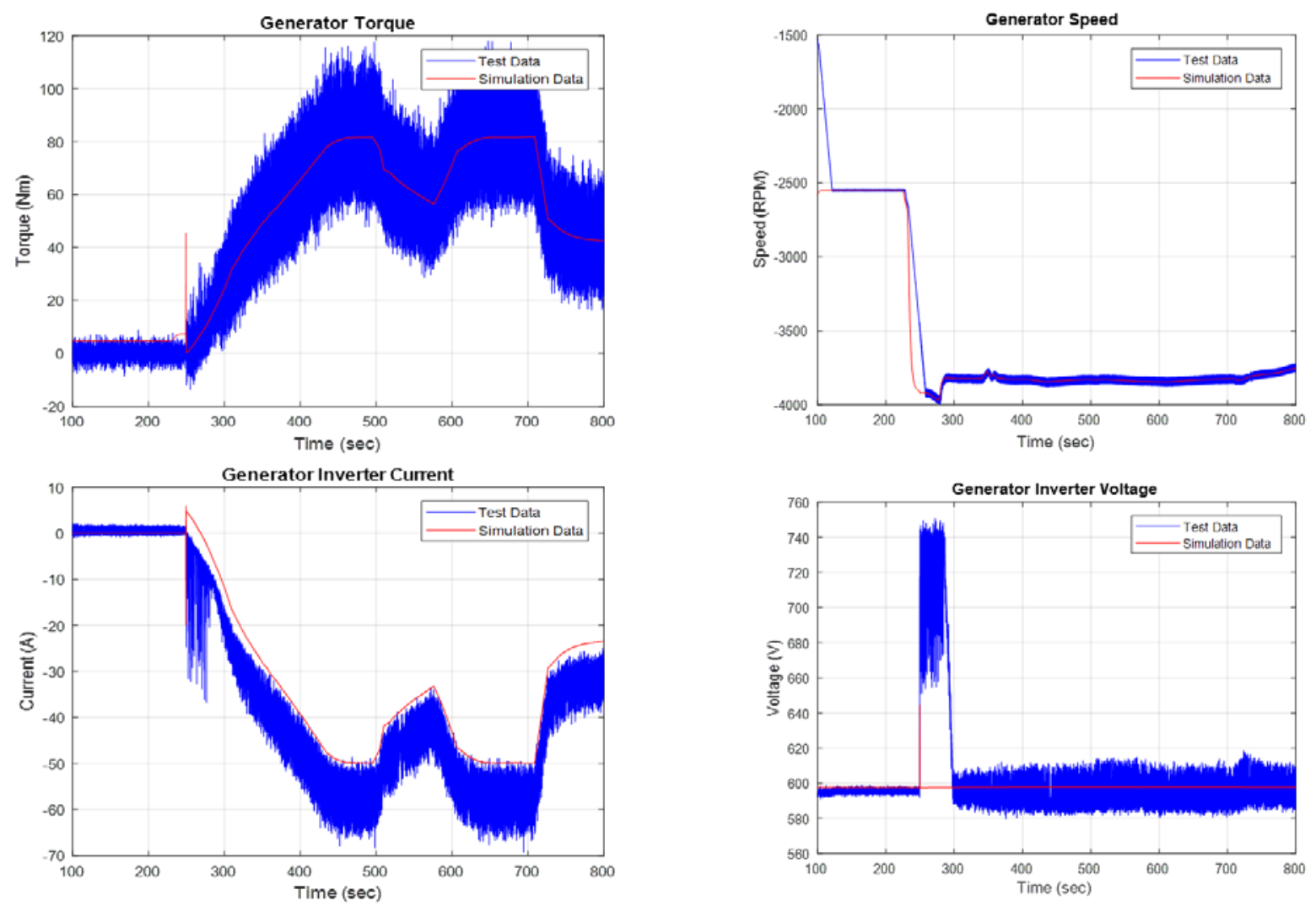

Figure 15. Generator M1 Model Validation 
Initial test results indicate very good agreement with model predictions for both the generator M1 shown in Fig. 15 and the tail-cone propulsor shown in Fig. 16. Note that the predominant error was during short startup transients but for the vast majority of the flight profile we see excellent agreement.

Most recently, NEAT was successfully operated with the full 900 NM flight profile indicated in Fig. 17. This flight profile extended beyond 2 hours and fully tested all the integrated systems. The power budget of the system is found in the appendix. The challenges with operating this full profile included:

- Thermally managing the extended duration test

- Addressing EMI between the controls and inverter

- Load balancing the system due to millisecond communication delays between turbo-generators

- Minimizing bus transients/power quality improvement without adding bus energy storage and regenerating

- Fault management/buffering issues with a complex system

Full recorded results are available of this initial profile and additional post-processing of the data will be used to improve the powertrain fault and control systems. But this initial test indicates the 500kW STARC-ABL powertrain can be operated under a realistic flight profile utilizing COTS equipment. Powertrain operation and flight profile details are found in the Appendix.
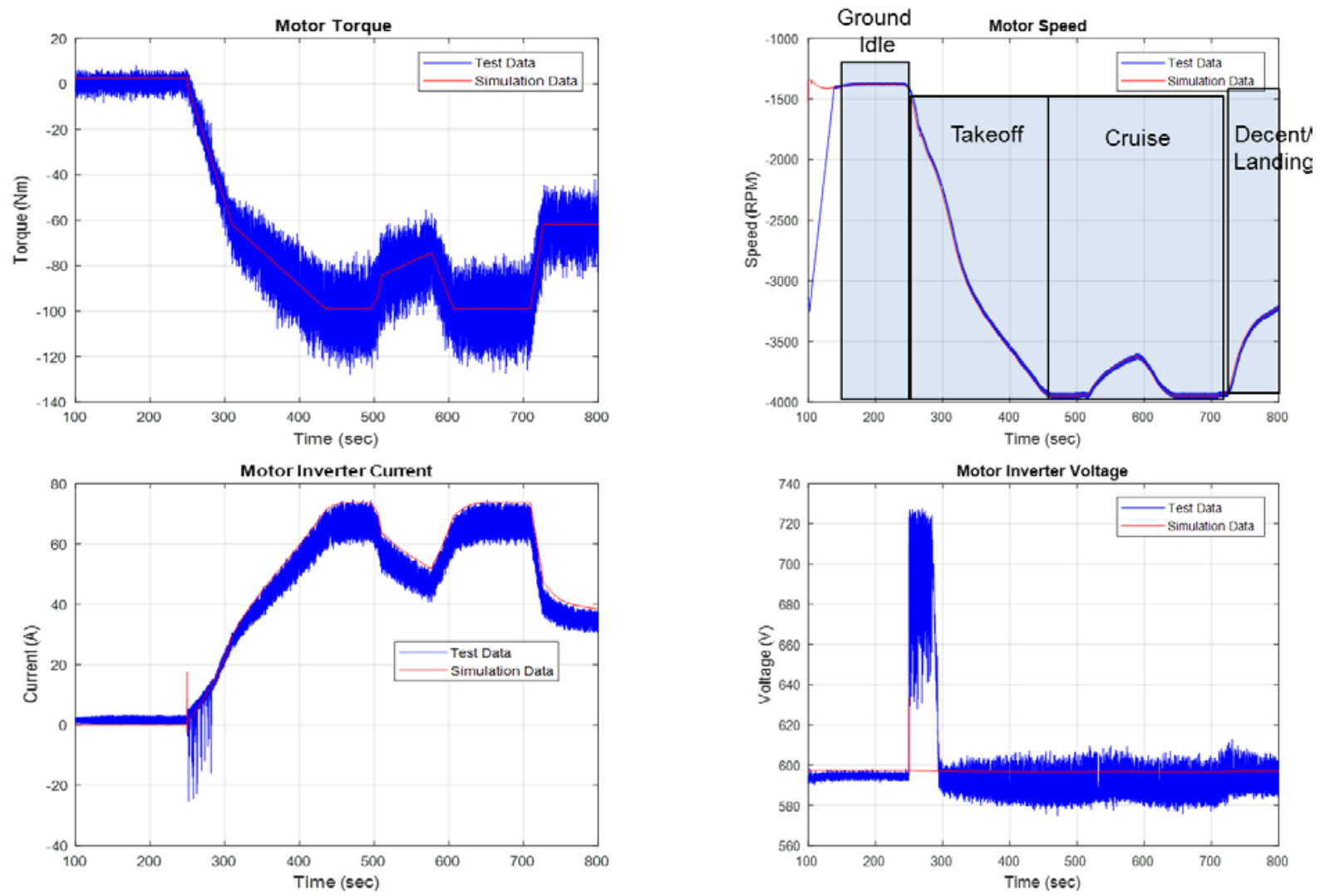

Figure 16. Motor M3 Model Validation 


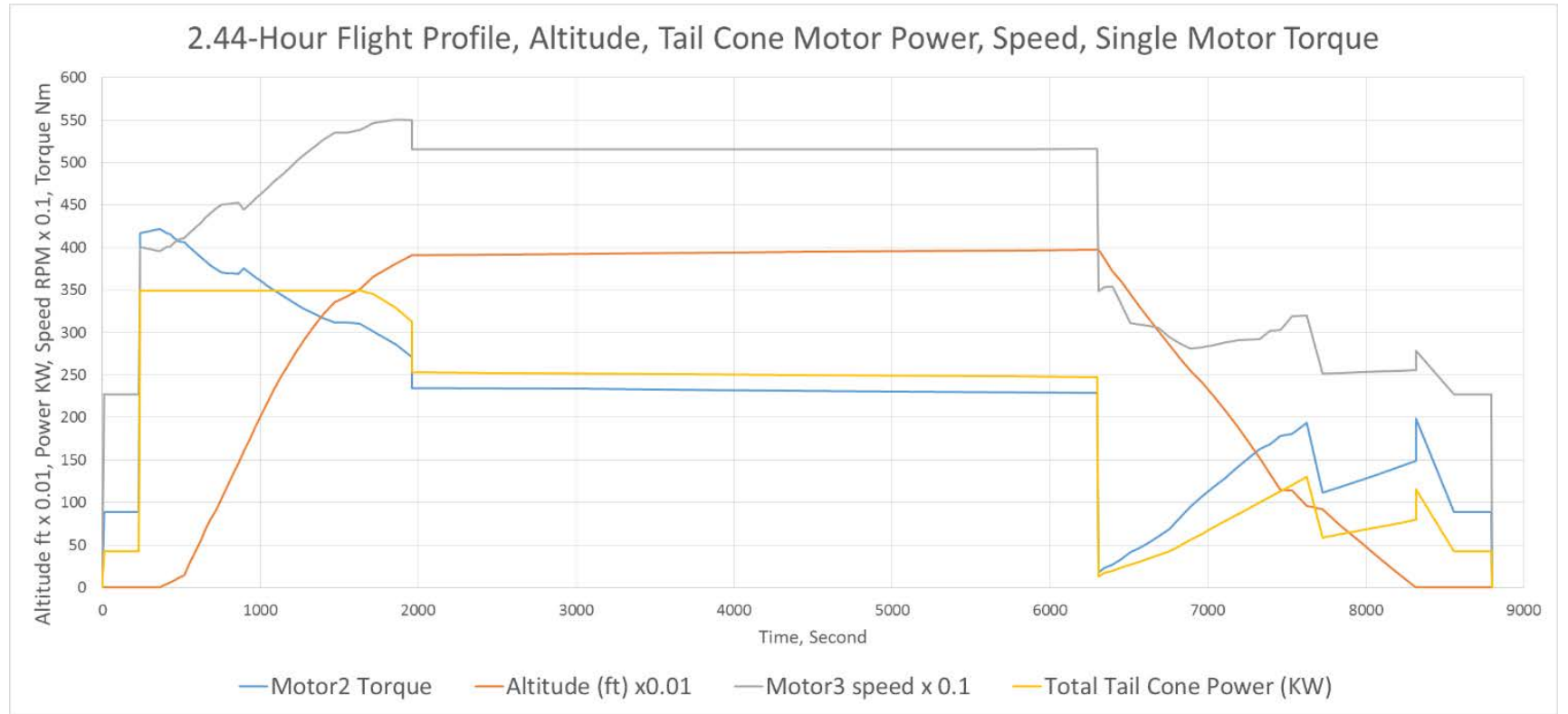

Figure 17. NEAT STARC-ABL Powertrain Testing for 900 NM Flight Profile 


\section{Lessons Learned and Next Steps}

The build-up of a complex electric aircraft powertrain requires integrating power, propulsion, and thermal components with sufficient control and fault response to protect full-scale, high power, high value research hardware. The simplest building block is based on the single-string as shown in Fig. 10 comprised of two shaft connected machine operating as a turbine-generator or propulsor-ducted fan combination. Some of the lessons learned include:

- EMI shielding is critical for safe and proper operation of the powertrain even with DO-160G compatible equipment

- Federated fault response with localized feedback/controls are important for orderly shutdown sequencing

- Electric machines can be scaled and controlled to simulate a turbine and ducted fan operation

- System interactions between components must be tested to account for common modes, grounding loops, electrical and mechanical resonant conditions

- Spline coupling selection impacts controllability

- Turbine and Electric Powertrain modeling can be very accurate if the component controls are fully characterized

- Optical fiber and digital instrumentation are required for robust communication and sensors

- Higher voltage and current present new issues such as insulation resistance breakdown and power quality challenges when operating near rated equipment limits

- Torque measurements are effected by cogging, EMI, torsional resonance, spline back-lash, and acquisition rates

- Shielding throughout the powertrain limits the ability to acquire data from transducers forcing calculated results via inverter software measurements.

The next steps of NEAT development are shown in Figs. 18-19. First, we successfully completed the single-string test in FY17 (shown in Fig. 10). Next we built and successfully tested the STARC-ABL configuration with a 500kW tail-cone thruster. Our next steps include doubling the tail-cone thruster power to $1 \mathrm{MW}$, adding triple control redundancy, adding smart energy storage, incorporate complete closed loop engine control with fan speed feedback to enable real-time turbine and fan emulation, and beginning to address proper aircraft grounding. 


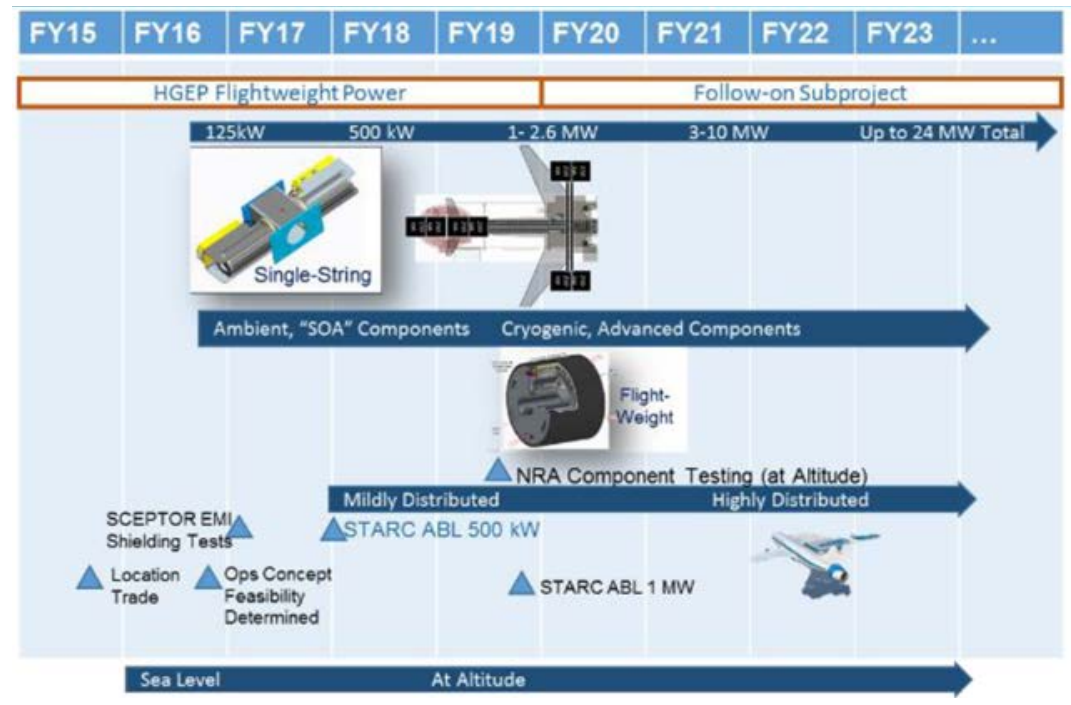

Figure 18. Research Plan

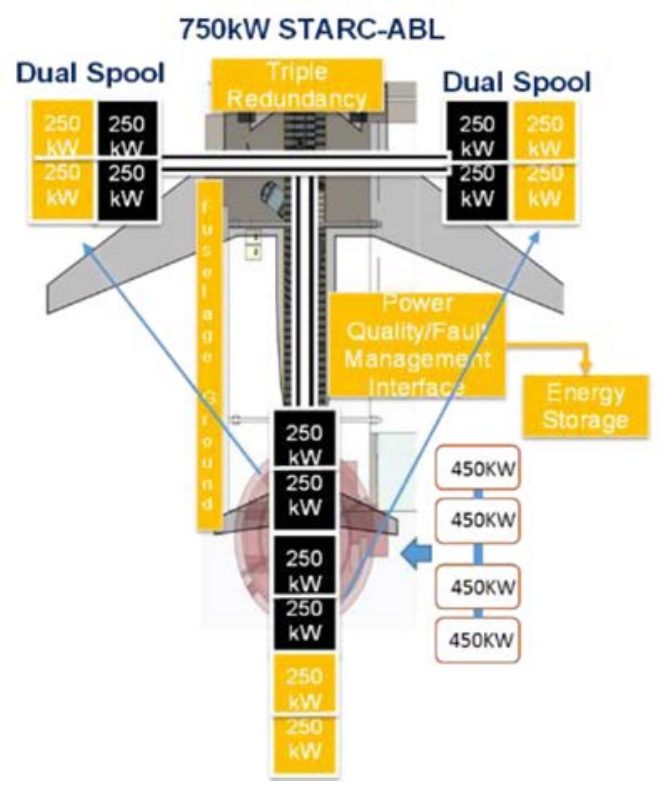

Figure19. Incorporating Flight Readiness

\section{Conclusion}

Full-scale electric aircraft testing is important because of the EMI, thermal management, cable impedance, fault response, and high voltage effects on the performance of the powertrain. A novel approach that utilizes a regenerative power strategy with machine pairs that emulate in real-time the turbine and propulsors was presented. A full $900 \mathrm{NM}$ flight-profile was successfully demonstrated at NEAT. Initial results indicate the importance of a smart fault management/energy storage component on the DC bus in addition to managing EMI and grounding challenges. The next steps are to increase the power level and incorporate flight-readiness features such as proper fuselage grounding, triple control redundancy, dual spool power extraction, and intelligent fault management. 


\section{Appendix}

Table 1. STARC-ABL Power Budget

\begin{tabular}{|c|c|c|c|c|c|c|c|c|c|c|c|c|c|c|}
\hline \begin{tabular}{|l|}
$0.5 \mathrm{MW}$ \\
Wing Tip \\
Speed \\
Motor Shaft \\
Power
\end{tabular} & $<<$ & $\begin{array}{l}0.5 \mathrm{MW} \\
\text { Wing Tip } \\
\text { Speed } \\
\text { Motor Input } \\
\text { Power }\end{array}$ & $<<$ & \begin{tabular}{|l|}
$0.5 \mathrm{MW}$ \\
Wing Tip \\
Speed \\
Inverter \\
Input \\
Power \\
\end{tabular} & $<<$ & \begin{tabular}{|l}
$0.5 \mathrm{MW}$ \\
Wing Tip \\
Speed \\
Inverter \\
Input \\
Power \\
\end{tabular} & & \begin{tabular}{|l|}
$0.5 \mathrm{MW}$ \\
Wing Tip \\
Torque \\
Motor \\
Output \\
Power \\
\end{tabular} & $\gg$ & \begin{tabular}{|l|}
$0.5 \mathrm{MW}$ \\
Wing Tip \\
Torque \\
Inverter \\
Output \\
Power \\
\end{tabular} & $\gg$ & \begin{tabular}{|l}
$2 \times 0.5 \mathrm{MW}$ \\
Wing Tip \\
Torque \\
Inverter \\
Output \\
Power \\
\end{tabular} & & \\
\hline \multirow[t]{2}{*}{$\begin{array}{l}0.5 \mathrm{MW} \text { Tail } \\
\text { Speed } \\
\text { Inverter } \\
\text { Output } \\
\text { Power } \\
\end{array}$} & $\gg$ & \begin{tabular}{|l|}
$0.5 \mathrm{MW}$ Tail \\
Speed \\
Motor Shaft \\
Power
\end{tabular} & $\gg$ & \begin{tabular}{|l|}
$0.5 \mathrm{MW}$ Tail \\
Torque \\
Motor \\
Output \\
Power \\
\end{tabular} & $\gg$ & $\begin{array}{l}0.5 \mathrm{MW} \text { Tail } \\
\text { Torque } \\
\text { Inverter } \\
\text { Output } \\
\text { Power }\end{array}$ & $>>$ & \begin{tabular}{|l}
$2 \times 0.5 \mathrm{MW}$ \\
Tail Torque \\
Inverter \\
Output \\
Power \\
\end{tabular} & & \begin{tabular}{|l|} 
DC Power \\
Supply \\
Output \\
Power
\end{tabular} & & & & \\
\hline & \multicolumn{4}{|c|}{ 0.5MW Wing Tip Speed Motor } & \multicolumn{3}{|c|}{ Inverter (DC to 3-Phase AC) } & \multicolumn{4}{|c|}{ Wire Loss (DC Supply to Inverter)@50 $0^{\circ} \mathrm{C}$} & & \multirow{2}{*}{\begin{tabular}{|l} 
Total Wing \\
Tip Speed \\
Inverter \\
Input \\
Power w/
\end{tabular}} & \multirow{2}{*}{$\begin{array}{l}2 \times \text { Wing Tip } \\
\text { Inverter } \\
\text { Input } \\
\text { Power (KW) }\end{array}$} \\
\hline \begin{tabular}{|l|} 
DC Link \\
Voltage $(\mathrm{V})$
\end{tabular} & \begin{tabular}{|l} 
Max Power \\
Output at \\
Motor Shaft \\
(W) \\
\end{tabular} & Efficiency & $\begin{array}{l}\text { Power Loss } \\
\text { (W) }\end{array}$ & \begin{tabular}{|l|} 
Motor Input \\
Power (W)
\end{tabular} & Efficiency & $\begin{array}{l}\text { Power Loss } \\
\text { (W) }\end{array}$ & \begin{tabular}{|l|} 
Input \\
Power (W)
\end{tabular} & $\begin{array}{l}\text { 4/0 AWG } \\
\text { Total } 30 \\
\text { feet (W) }\end{array}$ & \begin{tabular}{|l} 
Voltage \\
Drop (V)
\end{tabular} & $\begin{array}{l}\text { 3/0 AWG } \\
\text { Total } 30 \\
\text { feet (W) }\end{array}$ & \begin{tabular}{|l} 
Voltage \\
Drop (V)
\end{tabular} & \begin{tabular}{|l|} 
DC Link \\
Current at \\
Max Power \\
(A) \\
\end{tabular} & & \\
\hline \multirow[t]{2}{*}{700} & 500,000 & 0.98 & 10,204 & 510,204 & 0.98 & 10,412 & 520,616 & 909 & 1.22 & 1147 & 1.54 & 744 & 522 & 1043.1 \\
\hline & \multicolumn{4}{|c|}{ 0.5MW Wing Tip Torque Motor } & \multicolumn{3}{|c|}{ Inverter (3-Phase AC to DC) } & \multicolumn{4}{|c|}{ Wire Loss (Inverter to DC Supply)@50C } & \multirow{2}{*}{$\begin{array}{l}\text { DC Output } \\
\text { Current at } \\
\text { Max } \\
\text { Power (A) }\end{array}$} & \multirow{2}{*}{\begin{tabular}{|l} 
Total \\
Torque \\
Inverter \\
Output \\
Power w/
\end{tabular}} & \multirow{2}{*}{\begin{tabular}{|l}
$2 \times$ Torque \\
Inverter \\
Output \\
Power (KW)
\end{tabular}} \\
\hline $\begin{array}{l}\text { DC Link } \\
\text { Voltage } \\
(\mathrm{V})\end{array}$ & $\begin{array}{l}\text { Max Shaft } \\
\text { Input } \\
\text { Power (W) }\end{array}$ & Efficiency & $\begin{array}{l}\text { Power } \\
\text { Loss (W) }\end{array}$ & \begin{tabular}{|l|} 
Motor \\
Output \\
Power (W)
\end{tabular} & Efficiency & $\begin{array}{l}\text { Power } \\
\text { Loss (W) }\end{array}$ & \begin{tabular}{|l|} 
Output \\
Power (W)
\end{tabular} & $\begin{array}{l}\text { 4/0 AWG } \\
\text { Total } 30 \\
\text { feet }(W)\end{array}$ & $\begin{array}{l}\text { Voltage } \\
\text { Drop (V) }\end{array}$ & $\begin{array}{l}\text { 3/0 AWG } \\
\text { Total } 30 \\
\text { feet (W) }\end{array}$ & $\begin{array}{l}\text { Voltage } \\
\text { Drop (V) }\end{array}$ & & & \\
\hline \multirow[t]{2}{*}{700} & 500,000 & 0.98 & 10,000 & 490,000 & 0.98 & 9,800 & 480,200 & 774 & 1.13 & 975 & 1.42 & 686 & 479 & 958.9 \\
\hline & \multicolumn{4}{|c|}{$0.5 \mathrm{MW}$ Tail Speed Motor } & \multicolumn{3}{|c|}{ Tail Speed Inverter (DC to 3- } & \multicolumn{4}{|c|}{ Wire Loss (DC Supply to Inverter)@50C } & & \multirow[b]{2}{*}{\begin{tabular}{|l} 
Total Tail \\
Speed \\
Inverter \\
Input \\
Power w/ \\
$4 / 0$ AWG \\
wire (KW)
\end{tabular}} & \multirow{2}{*}{\begin{tabular}{|l}
$2 \times$ Tail \\
Speed \\
Inverter \\
Input \\
Power (KW)
\end{tabular}} \\
\hline $\begin{array}{l}\text { DC Link } \\
\text { Voltage } \\
\text { (V) }\end{array}$ & \begin{tabular}{|l|} 
Max \\
Power \\
Output at \\
Motor \\
Shaft \\
$(\mathrm{KW})$ \\
\end{tabular} & Efficiency & $\begin{array}{l}\text { Power } \\
\text { Loss (KW) }\end{array}$ & & Efficiency & $\begin{array}{l}\text { Power } \\
\text { Loss (KW) }\end{array}$ & \begin{tabular}{|l} 
Output \\
Power \\
(KW)
\end{tabular} & $\begin{array}{l}\text { 4/0 AWG } \\
\text { Total } 30 \\
\text { feet (W) }\end{array}$ & $\begin{array}{l}\text { Voltage } \\
\text { Drop (V) }\end{array}$ & $\begin{array}{l}\text { 3/0 AWG } \\
\text { Total } 30 \\
\text { feet (W) }\end{array}$ & $\begin{array}{l}\text { Voltage } \\
\text { Drop (V) }\end{array}$ & \begin{tabular}{|l|} 
DC Input \\
Current at \\
Max \\
Power (A) \\
\end{tabular} & & \\
\hline \multirow[t]{3}{*}{700} & 460 & 0.98 & 9 & & 0.98 & 10 & 470 & 771 & 1.13 & 972 & 1.42 & 685 & 479 & 958.9 \\
\hline & & & & & & & & & & & & & & \\
\hline & \multicolumn{4}{|c|}{ 0.5MW Tail Torque Motor } & \multicolumn{3}{|c|}{ Torque Inverter (3-Phase AC to } & \multicolumn{4}{|c|}{ Wire Loss (Inverter to DC Supply)@50 C } & \multirow{2}{*}{$\begin{array}{l}\text { DC Output } \\
\text { Current at } \\
\text { Max } \\
\text { Power (A) }\end{array}$} & \multirow[b]{2}{*}{\begin{tabular}{|l} 
Total \\
Torque \\
Inverter \\
Output \\
Power w/
\end{tabular}} & \multirow{2}{*}{$\begin{array}{l}2 \times \text { Torque } \\
\text { Inverter } \\
\text { Output } \\
\text { Power (KW) }\end{array}$} \\
\hline $\begin{array}{l}\text { DC Link } \\
\text { Voltage } \\
\text { (V) }\end{array}$ & \begin{tabular}{|l|} 
Max Shaft \\
Input \\
Power \\
(KW) \\
\end{tabular} & Efficiency & $\begin{array}{l}\text { Power } \\
\text { Loss (KW) }\end{array}$ & \begin{tabular}{|l} 
Motor \\
Output \\
Power \\
(KW) \\
\end{tabular} & Efficiency & $\begin{array}{l}\text { Power } \\
\text { Loss (KW) }\end{array}$ & \begin{tabular}{|l} 
Output \\
Power \\
(KW)
\end{tabular} & $\begin{array}{l}\text { 4/0 AWG } \\
\text { Total } 30 \\
\text { feet }(W)\end{array}$ & $\begin{array}{l}\text { Voltage } \\
\text { Drop (V) }\end{array}$ & $\begin{array}{l}\text { 3/0 AWG } \\
\text { Total } 30 \\
\text { feet }(W)\end{array}$ & $\begin{array}{l}\text { Voltage } \\
\text { Drop (V) }\end{array}$ & & & \\
\hline 700 & 460 & 0.98 & 9 & 451 & 0.98 & 9 & 442 & 656 & 1.04 & 827 & 1.31 & 632 & 442 & 883.1 \\
\hline
\end{tabular}

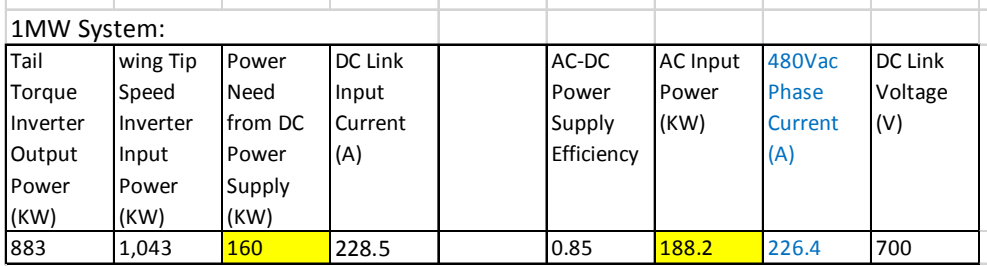


Table 2. STARC-ABL 900 NM Flight Profile

\begin{tabular}{|c|c|c|c|c|c|c|c|}
\hline Flight Segment & Time (min) & Altitude $(\mathrm{ft})$ & Mach & Fuel Flow (lbs/hr) & Onboard Fuel (lbs) & Net Thrust (lbs) & Tail Cone Power (HP) \\
\hline \multirow[t]{2}{*}{ Taxi } & 0 & 0 & 0.0000 & 765 & 8793 & 1171 & 422 \\
\hline & 4 & 0 & 0.0000 & 765 & 8742 & 1171 & 422 \\
\hline \multirow[t]{2}{*}{ Takeoff } & 4 & 0 & 0.0000 & 9540 & 8742 & 9293 & 3500 \\
\hline & 6 & 0 & 0.3000 & 9540 & 8424 & 28795 & 3500 \\
\hline \multirow[t]{32}{*}{ Segment 1 Climb } & 6 & 0 & 0.3000 & 9946 & 8424 & 28795 & 3500 \\
\hline & 6.34 & 190 & 0.3177 & 9426 & 8368 & 26445 & 3500 \\
\hline & 6.71 & 396 & 0.4806 & 9161 & 8311 & 19562 & 3500 \\
\hline & 7.11 & 620 & 0.4918 & 8944 & 8251 & 19092 & 3500 \\
\hline & 7.53 & 854 & 0.6000 & 8663 & 8189 & 18811 & 3500 \\
\hline & 8.04 & 1139 & 0.6595 & 8489 & 8117 & 18371 & 3500 \\
\hline & 8.61 & 1457 & 0.6649 & 8387 & 8037 & 18104 & 3500 \\
\hline & 9.17 & 2766 & 0.6702 & 8265 & 7958 & 17808 & 3500 \\
\hline & 9.74 & 4086 & 0.6751 & 8125 & 7881 & 17484 & 3500 \\
\hline & 10.3 & 5415 & 0.6797 & 7966 & 7806 & 17131 & 3500 \\
\hline & 10.86 & 6755 & 0.6840 & 7789 & 7732 & 16749 & 3500 \\
\hline & 11.43 & 8108 & 0.6878 & 7593 & 7660 & 16340 & 3500 \\
\hline & 12 & 9153 & 0.7031 & 7475 & 7588 & 16250 & 3500 \\
\hline & 12.58 & 10518 & 0.7067 & 7178 & 7517 & 15827 & 3500 \\
\hline & 13.16 & 11883 & 0.7103 & 6949 & 7448 & 15428 & 3500 \\
\hline & 13.75 & 13249 & 0.7139 & 6721 & 7381 & 15055 & 3500 \\
\hline & 14.34 & 14614 & 0.7177 & 6488 & 7316 & 14708 & 3500 \\
\hline & 14.94 & 16017 & 0.7200 & 6257 & 7253 & 14321 & 3500 \\
\hline & 15.55 & 17484 & 0.7200 & 6043 & 7191 & 13833 & 3500 \\
\hline & 16.17 & 18950 & 0.7200 & 5830 & 7129 & 13345 & 3500 \\
\hline & 16.8 & 20417 & 0.7200 & 5617 & 7068 & 12857 & 3500 \\
\hline & 17.47 & 21883 & 0.7200 & 5404 & 7008 & 12369 & 3500 \\
\hline & 18.16 & 23349 & 0.7200 & 5191 & 6947 & 11881 & 3500 \\
\hline & 18.88 & 24816 & 0.7200 & 4977 & 6885 & 11393 & 3500 \\
\hline & 19.65 & 26282 & 0.7200 & 4764 & 6823 & 10905 & 3500 \\
\hline & 20.47 & 27748 & 0.7200 & 4551 & 6759 & 10417 & 3500 \\
\hline & 21.34 & 29215 & 0.7200 & 4338 & 6695 & 9929 & 3500 \\
\hline & 22.29 & 30681 & 0.7200 & 4125 & 6628 & 9441 & 3500 \\
\hline & 23.32 & 32147 & 0.7200 & 3911 & 6559 & 8953 & 3500 \\
\hline & 24.47 & 33568 & 0.7220 & 3704 & 6486 & 8473 & 3500 \\
\hline & 25.76 & 34181 & 0.7582 & 3630 & 6407 & 8250 & 3500 \\
\hline & 27.19 & 35094 & 0.7812 & 3581 & 6321 & 8106 & 3498 \\
\hline \multirow[t]{4}{*}{ Segment 2 Climb } & 27.19 & 35094 & 0.7812 & 3581 & 6321 & 8106 & 3498 \\
\hline & 28.57 & 36529 & 0.7750 & 3426 & 6241 & 7732 & 3457 \\
\hline & 30.97 & 38117 & 0.7850 & 3232 & 6107 & 7250 & 3296 \\
\hline & 32.63 & 39116 & 0.7850 & 3071 & 6020 & 6876 & 3130 \\
\hline \multirow[t]{5}{*}{ Cruise } & 32.63 & 39116 & 0.7850 & 2441 & 6020 & 5534 & 2538 \\
\hline & 51.49 & 39273 & 0.7850 & 2428 & 5255 & 5500 & 2522 \\
\hline & 73.8 & 39463 & 0.7850 & 2412 & 4355 & 5460 & 2503 \\
\hline & 96.26 & 39656 & 0.7850 & 2397 & 3455 & 5420 & 2485 \\
\hline & 104.96 & 39732 & 0.7850 & 2391 & 3108 & 5404 & 2478 \\
\hline \multirow[t]{27}{*}{ Descent } & 104.96 & 39732 & 0.7850 & 412 & 3108 & 0 & 129 \\
\hline & 105.71 & 38783 & 0.7553 & 431 & 3103 & 0 & 169 \\
\hline & 106.6 & 37255 & 0.7422 & 439 & 3096 & 0 & 198 \\
\hline & 107.52 & 35976 & 0.7164 & 465 & 3089 & 0 & 234 \\
\hline & 108.47 & 34522 & 0.6944 & 487 & 3082 & 0 & 270 \\
\hline & 109.45 & 33051 & 0.6731 & 509 & 3074 & 0 & 303 \\
\hline & 110.46 & 31603 & 0.6505 & 535 & 3065 & 0 & 344 \\
\hline & 111.5 & 30121 & 0.6294 & 559 & 3055 & 0 & 385 \\
\hline & 112.58 & 28554 & 0.6124 & 583 & 3045 & 0 & 426 \\
\hline & 113.68 & 27078 & 0.5907 & 618 & 3034 & 0 & 492 \\
\hline & 114.81 & 25503 & 0.5739 & 654 & 3022 & 0 & 560 \\
\hline & 115.99 & 24171 & 0.5440 & 713 & 3009 & 0 & 632 \\
\hline & 117.22 & 22529 & 0.5306 & 754 & 2994 & 0 & 706 \\
\hline & 118.47 & 20887 & 0.5171 & 804 & 2977 & 0 & 782 \\
\hline & 119.72 & 19026 & 0.5160 & 844 & 2960 & 0 & 857 \\
\hline & 120.93 & 17146 & 0.5160 & 883 & 2943 & 0 & 930 \\
\hline & 122.1 & 15265 & 0.5160 & 922 & 2925 & 0 & 1001 \\
\hline & 123.22 & 13385 & 0.5160 & 974 & 2907 & 0 & 1069 \\
\hline & 124.29 & 11504 & 0.5160 & 1028 & 2889 & 0 & 1134 \\
\hline & 125.55 & 11442 & 0.4099 & 1290 & 2865 & 0 & 1210 \\
\hline & 127.09 & 9587 & 0.4099 & 1375 & 2831 & 0 & 1303 \\
\hline & 128.76 & 9179 & 0.3000 & 623 & 2803 & 0 & 589 \\
\hline & 130.62 & 7344 & 0.3000 & 645 & 2784 & 0 & 627 \\
\hline & 132.55 & 5508 & 0.3000 & 667 & 2762 & 0 & 666 \\
\hline & 134.53 & 3672 & 0.3000 & 705 & 2740 & 0 & 708 \\
\hline & 136.55 & 1836 & 0.3000 & 750 & 2715 & 0 & 752 \\
\hline & 138.6 & 0 & 0.3000 & 796 & 2689 & 0 & 798 \\
\hline \multirow[t]{2}{*}{ Approach } & 138.6 & 0 & 0.3000 & 1889 & 2689 & 1889 & 1159 \\
\hline & 142.6 & 0 & 0.0000 & 1171 & 2587 & 1171 & 422 \\
\hline Taxi & 142.6 & 0 & 0.0000 & 765 & 2587 & 1171 & 422 \\
\hline & 146.6 & 0 & 0.0000 & 765 & 2536 & 1171 & 422 \\
\hline
\end{tabular}


Table 3. Scaled Profile Successfully Operated

\begin{tabular}{|c|c|c|c|c|c|c|c|c|c|c|c|c|c|c|}
\hline Flight Segment & Time (Sec) & Altitude $(\mathrm{ft})$ & \begin{tabular}{|l}
$13.4 \%$ of Tail \\
Cone Power \\
(KW)
\end{tabular} & \begin{tabular}{|l|}
$10 \%$ of Tail Cone \\
Power (KW)
\end{tabular} & \begin{tabular}{|l|} 
e Tail Motor \\
Speed, $2: 1$ of \\
Fan Speed \\
(RPM)
\end{tabular} & \begin{tabular}{|l|} 
Tail Cone Motor \\
Torque, per \\
motor $(\mathrm{Nm})$
\end{tabular} & Motor1 Torque & Motor2 Torque & Motor3 speed & Motor4 torque & Motor5 Speed & Motor6 Speed & Motor7 torque & Motor8 torque \\
\hline Startup & 0 & 0 & 0 & 0 & 0 & 0 & 10 & 0 & 0 & 0 & 0 & 0 & 0 & 0 \\
\hline \multirow{2}{*}{ Taxi } & 10 & 0 & 42 & 31 & 2269 & 66 & 66 & 66 & 2269 & -66 & 2269 & 2269 & 66 & -66 \\
\hline & 230 & 0 & 42 & 31 & 2269 & 66 & 66 & 66 & 2269 & -66 & 2269 & 2269 & 66 & -66 \\
\hline Takeoff & 240 & 0 & 350 & 261 & 4004 & 311 & 311 & 311 & 4004 & -311 & 4004 & 4004 & 311 & -311 \\
\hline \multirow[t]{33}{*}{ Segment 1 Climb } & 360 & 0 & 350 & 261 & 3955 & 315 & 315 & 315 & 3955 & -315 & 3955 & 3955 & 315 & -315 \\
\hline & 380 & 190 & 350 & 261 & 3974 & 314 & 314 & 314 & 3974 & -314 & 3974 & 3974 & 314 & -314 \\
\hline & 403 & 396 & 350 & 261 & 4007 & 311 & 311 & 311 & 4007 & -311 & 4007 & 4007 & 311 & -311 \\
\hline & 427 & 620 & 350 & 261 & 4011 & 311 & 311 & 311 & 4011 & -311 & 4011 & 4011 & 311 & -311 \\
\hline & 452 & 854 & 350 & 261 & 4058 & 307 & 307 & 307 & 4058 & -307 & 4058 & 4058 & 307 & -307 \\
\hline & 482 & 1139 & 350 & 261 & 4097 & 304 & 304 & 304 & 4097 & -304 & 4097 & 4097 & 304 & -304 \\
\hline & 517 & 1457 & 350 & 261 & 4112 & 303 & 303 & 303 & 4112 & -303 & 4112 & 4112 & 303 & -303 \\
\hline & 550 & 2766 & 350 & 261 & 4168 & 299 & 299 & 299 & 4168 & -299 & 4168 & 4168 & 299 & -299 \\
\hline & 584 & 4086 & 350 & 261 & 4226 & 295 & 295 & 295 & 4226 & -295 & 4226 & 4226 & 295 & -295 \\
\hline & 618 & 5415 & 350 & 261 & 4285 & 291 & 291 & 291 & 4285 & -291 & 4285 & 4285 & 291 & -291 \\
\hline & 652 & 6755 & 350 & 261 & 4347 & 287 & 287 & 287 & 4347 & -287 & 4347 & 4347 & 287 & -287 \\
\hline & 686 & 8108 & 350 & 261 & 44407 & 283 & 283 & 283 & 4407 & -283 & 4407 & 4407 & 283 & -283 \\
\hline & 720 & 9153 & 350 & 261 & 44461 & 279 & 279 & 279 & 4461 & -279 & 4461 & 4461 & 279 & -279 \\
\hline & 755 & 10518 & 350 & 261 & 4502 & 277 & 277 & 277 & 4502 & -277 & 4502 & 4502 & 277 & -277 \\
\hline & 790 & 11883 & 350 & 261 & 4511 & 276 & 276 & 276 & 4511 & -276 & 4511 & 4511 & 276 & -276 \\
\hline & 825 & 13249 & 350 & 261 & 4520 & 276 & 276 & 276 & 4520 & -276 & 4520 & 4520 & 276 & -276 \\
\hline & 860 & 14614 & 350 & 261 & 4528 & 275 & 275 & 275 & 4528 & -275 & 4528 & 4528 & 275 & -275 \\
\hline & 896 & 16017 & 350 & 261 & 4450 & 280 & 280 & 280 & 4450 & -280 & 4450 & 4450 & 280 & -280 \\
\hline & 933 & 17484 & 350 & 261 & 4513 & 276 & 276 & 276 & 4513 & -276 & 4513 & 4513 & 276 & -276 \\
\hline & 970 & 18950 & 350 & 261 & 4575 & 272 & 272 & 272 & 4575 & -272 & 4575 & 4575 & 272 & -272 \\
\hline & 1008 & 20417 & 350 & 261 & 4639 & 269 & 269 & 269 & 4639 & -269 & 4639 & 4639 & 269 & -269 \\
\hline & 1048 & 21883 & 350 & 261 & 4710 & 265 & 265 & 265 & 4710 & -265 & 4710 & 4710 & 265 & -265 \\
\hline & 1090 & 23349 & 350 & 261 & \begin{tabular}{|l|l|}
4779 \\
\end{tabular} & 261 & 261 & 261 & 4779 & -261 & 4779 & 4779 & 261 & -261 \\
\hline & 1133 & 24816 & 350 & 261 & 4848 & 257 & 257 & 257 & 4848 & -257 & 4848 & 4848 & 257 & -257 \\
\hline & 1179 & 26282 & 350 & 261 & 4930 & 253 & 253 & 253 & 4930 & -253 & 4930 & 4930 & 253 & -253 \\
\hline & 1228 & 27748 & 350 & 261 & 5013 & 249 & 249 & 249 & 5013 & -249 & 5013 & 5013 & 249 & -249 \\
\hline & 1280 & 29215 & 350 & 261 & 5095 & 245 & 245 & 245 & 5095 & -245 & 5095 & 5095 & 245 & -245 \\
\hline & 1337 & 30681 & 350 & 261 & 5180 & 241 & 241 & 241 & 5180 & -241 & 5180 & 5180 & 241 & -241 \\
\hline & 1399 & 32147 & 350 & 261 & 5270 & 236 & 236 & 236 & 5270 & -236 & 5270 & 5270 & 236 & -236 \\
\hline & 1468 & 33568 & 350 & 261 & 5354 & 233 & 233 & 233 & 5354 & -233 & 5354 & 5354 & 233 & -233 \\
\hline & 1546 & 34181 & 350 & 261 & 5355 & 233 & 233 & 233 & 5355 & -233 & 5355 & 5355 & 233 & -233 \\
\hline & 1629 & 35094 & 350 & 261 & 53884 & 231 & 231 & 231 & 5384 & -231 & 5384 & 5384 & 231 & -231 \\
\hline & 1631 & 35094 & 350 & 261 & 5384 & 231 & 231 & 231 & 5384 & -231 & 5384 & 5384 & 231 & -231 \\
\hline \multirow{3}{*}{ Segment 2 Climb } & 1714 & 36529 & 345 & 258 & 5466 & 225 & 225 & 225 & 5466 & -225 & 5466 & 5466 & 225 & -225 \\
\hline & 1858 & 38117 & 329 & 246 & 5503 & 213 & 213 & 213 & 5503 & -213 & 5503 & 5503 & 213 & -213 \\
\hline & 1958 & 39116 & 313 & 233 & 5497 & 203 & 203 & 203 & 5497 & -203 & 5497 & 5497 & 203 & -203 \\
\hline Cruise & 1960 & 39116 & 254 & 189 & 5153 & 175 & 175 & 175 & 5153 & -175 & 5153 & 5153 & 175 & -175 \\
\hline & 3089 & 39273 & 252 & 188 & 5154 & 174 & 174 & 174 & 5154 & -174 & 5154 & 5154 & 174 & -174 \\
\hline & 4428 & 39463 & 250 & 187 & 5156 & 173 & 173 & 173 & 5156 & -173 & 5156 & 5156 & 173 & -173 \\
\hline & 5776 & 39656 & 248 & 185 & 5158 & 172 & 172 & 172 & 5158 & -172 & 5158 & 5158 & 172 & -172 \\
\hline & 6298 & 39732 & 248 & 185 & 5160 & 171 & 171 & 171 & 5160 & -171 & 5160 & 5160 & 171 & -171 \\
\hline Descent & 6308 & 39732 & 13 & 10 & 3487 & 13 & 13 & 13 & 3487 & -13 & 3487 & 3487 & 13 & -13 \\
\hline & 6343 & 38783 & 17 & 13 & 3534 & 17 & 17 & 17 & 3534 & -17 & 3534 & 3534 & 17 & -17 \\
\hline & 6396 & 37255 & 20 & 15 & 3546 & 20 & 20 & 20 & 3546 & -20 & 3546 & 3546 & 20 & -20 \\
\hline & 6451 & 35976 & 23 & 17 & 3330 & 25 & 25 & 25 & 3330 & -25 & 3330 & 3330 & 25 & -25 \\
\hline & 6508 & 34522 & 27 & 20 & 3113 & 31 & 31 & 31 & 3113 & -31 & 3113 & 3113 & 31 & -31 \\
\hline & 6567 & 33051 & 30 & 23 & 3095 & 35 & 35 & 35 & 3095 & -35 & 3095 & 3095 & 35 & -35 \\
\hline & 6628 & 31603 & 34 & 26 & 3076 & 40 & 40 & 40 & 3076 & -40 & 3076 & 3076 & 40 & -40 \\
\hline & 6690 & 30121 & 38 & 29 & 3057 & 45 & 45 & 45 & 3057 & -45 & 3057 & 3057 & 45 & -45 \\
\hline & 6755 & 28554 & 43 & 32 & 2952 & 51 & 51 & 51 & 2952 & -51 & 2952 & 2952 & 51 & -51 \\
\hline & 6821 & 27078 & 49 & 37 & 2873 & 61 & 61 & 61 & 2873 & -61 & 2873 & 2873 & 61 & -61 \\
\hline & 6889 & 25503 & 56 & 42 & 2807 & 71 & 71 & 71 & 2807 & -71 & 2807 & 2807 & 71 & -71 \\
\hline & 6959 & 24171 & 63 & 47 & 2829 & 79 & 79 & 79 & 2829 & -79 & 2829 & 2829 & 79 & -79 \\
\hline & 7033 & 22529 & 71 & 53 & 2850 & 88 & 88 & 88 & 2850 & -88 & 2850 & 2850 & 88 & -88 \\
\hline & 7108 & 20887 & 78 & 58 & 2887 & 96 & 96 & 96 & 2887 & -96 & 2887 & 2887 & 96 & -96 \\
\hline & 7183 & 19026 & 86 & 64 & 2910 & 105 & 105 & 105 & 2910 & -105 & 2910 & 2910 & 105 & -105 \\
\hline & 7256 & 17146 & 93 & 69 & 2919 & 113 & 113 & 113 & 2919 & -113 & 2919 & 2919 & 113 & -113 \\
\hline & 7326 & 15265 & 100 & 75 & 2928 & 122 & 122 & 122 & 2928 & -122 & 2928 & 2928 & 122 & -122 \\
\hline & 7393 & 13385 & 107 & 80 & 3020 & 126 & 126 & 126 & 3020 & -126 & 3020 & 3020 & 126 & -126 \\
\hline & 7457 & 11504 & 113 & 85 & 3028 & 133 & 133 & 133 & 3028 & -133 & 3028 & 3028 & 133 & -133 \\
\hline & 7533 & 11442 & 121 & 90 & 3192 & 135 & 135 & 135 & 3192 & -135 & 3192 & 3192 & 135 & -135 \\
\hline & 7625 & 9587 & 130 & 97 & 3203 & 145 & 145 & 145 & 3203 & -145 & 3203 & 3203 & 145 & -145 \\
\hline & 7726 & 9179 & 59 & 44 & 2517 & 83 & 83 & 83 & 2517 & -83 & 2517 & 2517 & 83 & -83 \\
\hline & 7837 & 7344 & 63 & 47 & 2525 & 88 & 88 & 88 & 2525 & -88 & 2525 & 2525 & 88 & -88 \\
\hline & 7953 & 5508 & 67 & 50 & 2532 & 94 & 94 & 94 & 2532 & -94 & 2532 & 2532 & 94 & -94 \\
\hline & 8072 & 3672 & 71 & 53 & 2540 & \begin{tabular}{|l|}
99 \\
\end{tabular} & 99 & 99 & 2540 & -99 & 2540 & 2540 & 99 & -99 \\
\hline & 8193 & 1836 & 75 & 56 & 2548 & 105 & 105 & 105 & 2548 & -105 & 2548 & 2548 & 105 & -105 \\
\hline & 8316 & 0 & 80 & 59 & 2556 & 111 & 111 & 111 & 2556 & -111 & 2556 & 2556 & 111 & -111 \\
\hline Approach & 8318 & 0 & 116 & 86 & 2784 & 148 & 148 & 148 & 2784 & -148 & 2784 & 2784 & 148 & -148 \\
\hline Taxi & 8556 & 0 & 42 & 31 & 2269 & 66 & 66 & 66 & 2269 & -66 & 2269 & 2269 & 66 & -66 \\
\hline & 8796 & 0 & 42 & 31 & 2269 & 66 & 66 & 66 & 2269 & -66 & 2269 & 2269 & 66 & -66 \\
\hline Shutdown & 8801 & 0 & & 0 & & 0 & 0 & 0 & & 00 & 0 & 0 & 0 & 0 \\
\hline
\end{tabular}




\section{Acknowledgments}

The author would like to thank Don Simon, Joe Connolly, Keith Hunker, Ralph Jansen, Cheryl Bowman, Amy Jankovsky, Gerald Hill, VPL staff, and TFOME staff, for making this work possible. In addition this work was financially supported by the Advanced Air Transportation Technology Project/Hybrid Gas Electric Propulsion Subproject.

\section{References}

AFDX, 2018. Avionics Full Duplex Switched Ethernet. [Online] Available at: https://en.wikipedia.org/wiki/Avionics_Full-Duplex_Switched_Ethernet Armstrong, M., 2015. Superconducting Turboelectric Distributed Aircraft Propulsion. Tucson, s.n. Choi, B., 2014. Propulsion Electric Grid Simulator (PEGS) for Future Turboelectric Distributed Propulsion Aircraft, Cleveland: NASA.

Clarke, S., 2015. Enabled Electric Propulsion For Flight - Hybrid Electric Aircraft Research at AFRC., s.l.: s.n.

Connolly, J. a. H. K., 2018. STARC-ABL Preliminary Sim Results. s.l.:Personal Communication.

Dyson, R., 2016. NASA Electric Aircraft Testbed (NEAT) Development Pan - Design, Fabrication, Installation, Cleveland: NASA/TM-2016-219085.

Dyson, R., 2017. Precious Metal, s.l.: Aerospace Testig International. Epstein, A., 2013. Aeropropulsion for Commercial Aviation in the 21st Century and Research Directions Needed. s.l., AIAA.

Jansen, R., 2015. Turboelectric Aircraft Drive Key Performance Parameters and Functional Requirements. s.l., AIAA.

Jansen, R. e. a., 2017. Overview of NASA Electrified Aircraft Propulsion (EAP) Research for Large Subsonic Transports. Atlanta, AIAA/SAE/ASEE.

Jones, C., 2016. Electrical Model of Carbon Fibre Reinforced Polymers for the Development of Electrical Protection Systems for More Electric Aircraft.

Jones, C. N. P., 2016. Electrical Model of Carbon Fibre Reinforced Polymers for the Development of Electrical Protection Systems for More-Electric Aircraft, s.l.: EPE.

Moffit, B., 2017. Analysis and Testing of Boundary-Layer-Ingesting Pusher Propeller for High Speed Rotorcraft, Fort Worth: AHS International.

Terorde, M., 2015. Phase Balancing for Aircraft Electrical Distribution Systems. IEEE Transactions on Aerospace and Electronics Systems, pp. Vol. 51, No. 3.

Welstead, J. a. F. J., 2016. Conceptual Design of a Single-Aisle Turboelectric Commercial Transport with Fuselage Boundary Layer Ingestion, San Diego: AIAA, 54th Aerospace Sciences Meeting. 